

\section{Measurement of the Central Ion and Electron Temperature of Tokamak \\ Plasmas from the X-Ray Line Radiation of High $z$ Impurity Ions*}

M. Bitter, s. von Goeler, M. Goldman, K.W. Hill, R. Horton,

W. Roney, N. SauthofE, and W. Stodiek

princeton Plasma Physics Laboratory,

Princeton, New Jersey 08544

PPP $-1,1391$

DE, 92012757

ABSTRACT

Hot tokamak plasmas contain small amounts of highly ionized, 7 igh $z$ impurity lons, such as tron and titanium, with charge-state distri: itions close to the ionization equilibrium of the solar corona. The characte istic $x-r a y$ line radiation of these lons represents a unique source of information on the plasma parameters. It is expected to be of vital importance in particular as a diagnostic of the central ion temperature in future large size tokamaks.

This paper describes measurements of the central jon and electron temperature of tokamak plasmas trom the observation of the $1 s$ - $2 p$ resonance lines, and the associated dielectronlc $\left(1 \mathrm{~s}^{2} \mathrm{l} l-1 \mathrm{~s} 2 \mathrm{p} l\right.$, with $\left.n \geq 2\right)$ sateliftes, of helium-1ike iron (Fe XXV) and titaniun (Ti XXI). The satelíite to resonance line ratiog are very sensitive to the electron temperature and are usea as an electron temperature diagnostic. The ion temperature is deduced from the Doppler with of the $1 \mathrm{~s}-2 \mathrm{p}$ resonance lines. The measurements have been performed with high resolution Bragg crystal spectrometers on the PLT (Princeton Large Torus) and PDX (Poloidal Divertor Experiment) tokamaks. The details of the experimental arrangement and 1 ine evaluation are described, and the lon and electron temperature results are compared with those obtalned from independent diagnostic techniques, such as the analysis of charge-exchange neutrals and measurements of the electron cyclotron radiacion. The obtalned experimental results permit a detalled comparison with theoretical predictions.

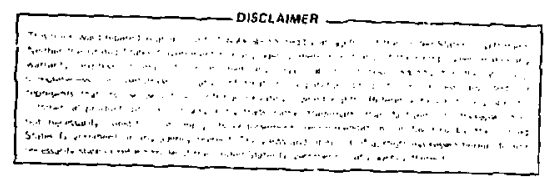

- Prepared for The sixth International symposiun on Temperature: Its Measurement and Control in Sclence and Industry, Washington, D.C., March 14-18, 1982. 


\section{INTRODUCTION}

In recent tokamak experiments, very high plasma temperatures have been obtained by the use of efficlent heating techniques, e.g., the injection of intense hydrogen or deuterium beams, 1 and the excltation and damping of plasma waves. 2 Lärge volumes of hydrogen plasmas with ion and electron temperatures of $\mathrm{T}_{\mathrm{i}}=i-7 \mathrm{keV}$ and $\mathrm{T}_{\mathrm{e}}=1-, \mathrm{kev}$, respectively, and densities of $1-5 \times 10^{13} \mathrm{~cm}^{-3}$ can now be malntalned in tokamak dischargeg for several hundred milliseconds. These encouraglng experimental results have motivated the design of tokamak fusion teat reactors. The prospective dimensions, plasma densitles, and temperatures for these devices exceed by far those of present-day tokanaks, and they should be adequate for the demongtration of "Eusion breakeven" which will be achleved if the released fusion energy is equal to the energy invested in heating the plasma.

As the dimensions, densities, and temperatures of tokamak plasmas increased, it became obvious that new diagnostic techniques were needed. ${ }^{3-5}$ This is true in particular for measurement of the tor temperature in the hot core of tokamak discharges, since the standard methods, i.e., the measurement of the energy distribution of charge-exchange neutrals, 6 and Dopplerbroadening measurements of spectral lines in the vov (vacuum ultraviolet) region, ${ }^{7}$ prove difficult under these experimental conditions. The chargeexchange diagnostic cannot be used for determination of the central ion temperature when the mean free path for neutral charge exchange is small compared with the diameter of the plasma, and IIne radiation in the vur region is primarily emitted from the edge of the plasma, If the central electron temperature is of the order of $1 \mathrm{kev}$. An exception $1 \mathrm{~s}$ the forbidden line of Fe $x x,{ }^{8}$ although this line will also originate from outer regions of the plasma column when the electron temperature exceeds $2 \mathrm{ksV}$. In this paper we 
discuss alternative methods for diagnostic of the central ion and electron temperature which are based on observation of the soft $x$-ray line radiation from helfum-like high $z$ impurity ions, e.g., Fe XXV and Ti XXI. These ions occur in the center of hot tokamak discharges for a wide range of experimental parameters.

The spectra of helium-like lons show, In addition to the characteristic hellum lines, a geries of satellites close to the 13 - $2 p$ resonance 1 ines. These satellites are due to transitions of the type $1 \mathrm{~s}^{2} \mathrm{n} t-1 \mathrm{spn} 9$ with $\mathrm{n} \geqq 2$ and are produced by dielectronic capture of electrons with well defined kinetic energies (in the range from $4.69 \mathrm{keV}$ to $6.7 \mathrm{keV}$, for Fe $\mathrm{xxV}$ ). The resonance lines are excited by electrons with energies larger than the is - 2p threshold energles $(6.7 \mathrm{keV}$ in $\mathrm{Fe} \mathrm{XXV})$. The intensity ratio of the resonance and satellite lines therefore depends strongly on the electron temperature and can be used for electron temperature measurements. In addition, certain satellite to resonance ine ratios can be used to measure the relative abundances of the lithium- and hellum-like charge states, thus providing a means for djagnostic of the ionization equilibrium and the impurity transport. Most Important for hot tokamak plasmas is, of course, the determination of the central ion temperature which is deduced from Doppler-broadening of the Ka-resonance lines of Fe XXV and Ti XXI at 1.85 and 2.61 \&. These measurements require Bragg crystal spectrometers of high . spectral resolution and intensity for time resolved observations. Competing with Doppler broadening are natural line broadening and the recently discovered dielectronlc broadening, 9,10 a pheomenon peculiar to high temperature plasmas.

Spectra of high $z$ hellum-like lons are also observed in solar flares, ${ }^{11-14}$ and a detailed theor $y^{9,15-17}$ of these spectra has been developed 
for diagnostics of the flare parameters. observations of these spectra in well diagnosed tokamak discharges permit a detailed comparison between experiment and theory and, therefore, are of great interegt.

We begin with a brief description of tokamak experiments (Sec. II) and discuss (Sec. III) the parameters, e.g., the electron temperature and density profiles, the charge-state digtribution and x-ray line emissivity for heliumlike impurity ions, which are relevant for the diagnostic application of these line spectra to tokamak plasmas. Sectionr, IV and $v$ degcribe the crystal spectrometers and the numerical methods which have been used for evaluation af line profiles. Section VI presents ion and electron temperature results obtained from observation of the Fe XXV- and Ti XXI- spectra on the PLT (Princeton Large Torus) and PDX (Poloidal Divertor Experiment) tokamaks at Princeton. These results are compared with those obtained from different diagnostic techniques, e.g., analysis of the energy distribution of charge-exchange neutrals and measurements of the electron cyclotron emission.

\section{THE TOKAMAK}

Basically, the tokamak is a ring of hot hydrogen plasma which is confined by a strong toroldal magnetic field inside a vacuum vessel. The plasma is produced by induction of an electric field which causes a current to flow in the toroidal direction. The current serves both to ohmically heat the plasma and to provide MHD equilibrium and stabilization by its poloidal magnetic field.

The stability of a tokamak plasma is a function of the aspect ratio $(R / a)$ of the major $(R)$ and minor (a) radil of tha torug. In general, small aspect ratiog are desired to obtain a stable plasma and to optimize ohmic heating efficiency. Also, the particle and energy confinement times are 
expected to increase in proportion to $a^{2}$. Therefore, short and fat tokamaks are better than long and thin ones. Here we list the parameterg of ELT which is one of the largest tokamaks in operation:

$\begin{array}{ll}\text { major radius: } & R=140 \mathrm{~cm} \\ \text { minor radius: } & a=40 \mathrm{~cm} \\ \text { toroidal magnetic field: } & B_{t}=32 \mathrm{kG} \\ \text { plasma current: } & I_{p}=500 \mathrm{kA} .\end{array}$

The duration of a discharge pulse is typlcally $;$ sec. The plasma can be maintained under steady-state conditions for perlods of 100 - 300 msec. A schematic of the PLT is shown in Fig. 1.

Tokamaks of comparable dimensions are presently in operation in the U.S. and abroad. The JET (Joint European Torus) and TFTR (Tokamak Fuston Test Reactorl tokamaks which have been designed to achleve "breakeven" in a deuterlum tritium plasma, are now under construction and have about twice the linear dimensions of the PLT.

The plasma densities and temperatures in tokamak alscharges are nearly constant in the toroidal direction and only vary with radius due to the fact that the iong and electrons move freely along (but not across) the magnetic Eield Iines. In general, the radial density and temperature profiles are peaked near the magnetic axis and decay parabolically or steeper towards the plasma boundary. The peak electron densitles and the electron and ion temperatures are typically in the range from $.1-1 \times 10^{14} \mathrm{~cm}^{-3}$, and $1-3$ kev, and $1-7 \mathrm{keV}$, raspectively. The maximum temperatures have been obtained in aischarges with additional heating by injection of intense deuterium beams ${ }^{1}$ or with rf heating. 2 High purity of the plasma is crucial for the success of 
these heating experiments. The tokamak has been reviewed in several articles. 19,20

\section{IMPURITIES}

Tokamak discharges contain small amounts (typicaliy.18) of Impurities, like carbon, oxygen, iron, chromium, nickel, and titanium. These elements enter the plasma from the wall of the vacuum vessel, and are lonized to different states of ionization or charge states. The radiation emitted from impurity ions consists of a bremsstrablung and recombination continuum and characteristic line spectra, and it contributes significantly to the total snergy loss of the plasma. Figure 2 presents a typical spectrum of the soft X-ray radiation emitted from PLT showing the relative contributions of the continum and line radiation from high $\mathrm{z}$ impurities ( $\mathrm{Cr}$, Fe, Ni). The data were observed with the PIT Pulse Height Analysis system, which essentially consists of a pinhole camera and diode detector with an energy resolution of $300 \mathrm{ev} \cdot 21$

The line radiation of the various impurity ions affects the plasma in different ways. Low $z$ elements like carbon and oxygen are fully stripped in the hot center of the discharge, whereas high $z$ ions like iron and titanium are only partially 1onized, the nighest state of ionization being the heliumlike charge state for typical central electron temperatures of 1-3 keV. Line radiation of low $z$ lons 1 , therefore, predominantly emitted from the edge of the plasma, whereas the line radiation of high $z$ ions is emitted from the center of the discharge. The energy losses associated with the line radiation from high $\mathrm{Z}$ long tend to reduce the temperature in the hot core of the plasma and are therefore a matter of concern. On the other hand, Iine radiation from Low $\mathrm{Z}$ inne provides cooling of the plasma periphery. This can, in fact, be 
beneficial in that low edge temperatures tend to reduce the influx of high $z$ wall impurities by reduction of sputtering. 4

The intensity of the observed impurtty line radiation depends on the radial distribution of the different stacies of iunization. The diatribution of the charge states of high $z$ ions, e.g., Fe $x x I V$ and $F e x x y$, is expected to he in equilibrium since the lonization and recombination timeg are usually small compared with the perlod of steady-state conditions in tokamak discharges. Moreover, since the electron densities are far below threshold for collisional deexcitation, these ions exist essentially only in their ground states. 15 one may therefore assume that the equilibrium charge-state distribution in tokamak plasmas is close to the so-called coronal equilibrium, 22-24 i.e., that the relative abundance of successive ionization states is determined by the ratlo of the recombination and ionization rate coefficients, e.g.,

$$
{ }_{\mathrm{Fe}} \times \mathrm{XIV}^{/ \mathrm{n}_{\mathrm{Fe}} \mathrm{XXV}}=\alpha / S=\mathrm{f}(\mathrm{T} \mathrm{e})
$$

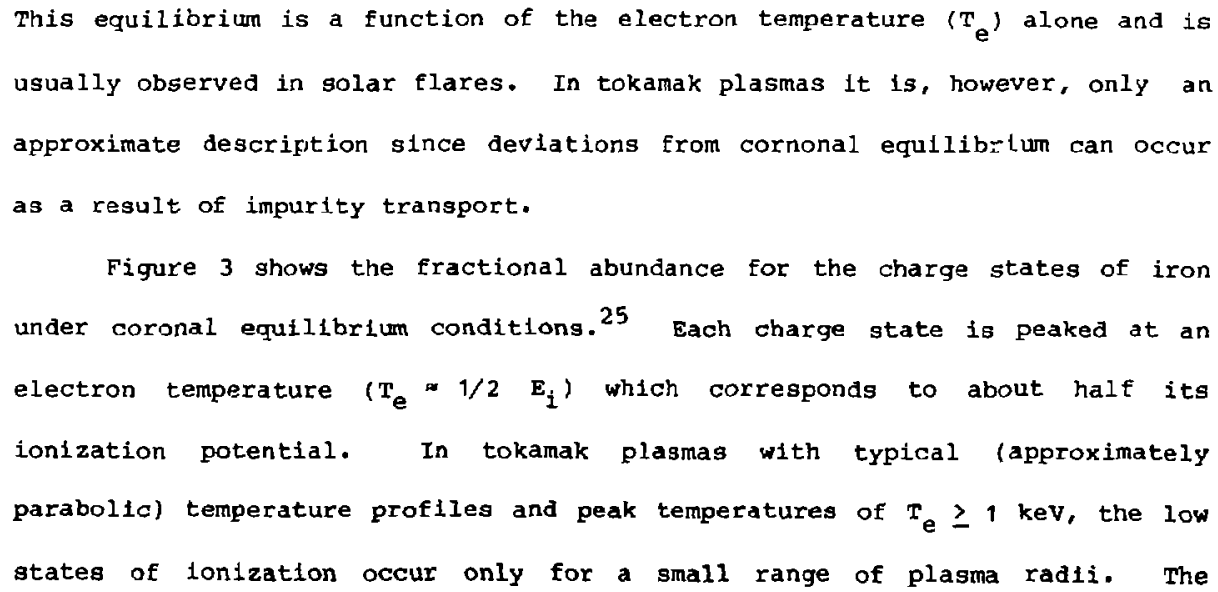
usually observed in solar flares. In tokamak plasmas it is, however, only an approximate description since deviations from cornonal equllibrtum can occur as a result of impurity transport.

Figure 3 ghows the fractional abundance for the charge states of iron under coronal equilibrium conditions. 25 Each charge state is peaked at an electron temperature $\left(T_{e}-1 / 2 \quad E_{i}\right)$ which corresponds to about half its ionlzation potential. In tokamak plasmas with typical (approximately parabolic) temperature profiles and peak temperatures of $T_{e} \geq 1$ kev, the low states of lonization occux only for a small range of plasma radit. The 
hellum-like charge state (Fe XXV) is produced in the core of tokamak discharges for (relatively low) central electron temperatures $\mathrm{T}_{\mathrm{e}}(0) \geq 1 \mathrm{keV}$ due to the small Ionization potential $\left(E_{1}=2.045 \mathrm{kev}\right)$ of lithium-11ke 1ron (Fe XXIV). On the other hand, since the fonization potential $\left(E_{i}=8.828 \mathrm{keV}\right.$ ) of Fe $x x V$ is very large, it exists for a wide range of sentral electron temperatures, being the dominant charge state for $\mathrm{T}_{\mathrm{e}}(0)$ in the range from 1.5 to $6 \mathrm{keV}$ and comparable with the fractional abundance of hydrogen-like iron, Fe $\mathrm{XXVI}$, for $\mathrm{T}_{\mathrm{e}}(0)$ in the range from 6 to $10 \mathrm{keV}$. The characteristic line radiation of Fe $\mathrm{XXV}$ is therefore well suited for diagnostics of central plasma parameters, both in present-day and in future larger size tokamaks.

An experimental investlgation of the charge-state distribution of iron in tokamak plasmas was performed on PLT using a Bragg curved crystal spectrometer. 26 These measurements were based on the observation of the characteristic $K \alpha-l i k g$ radiation emitted by the different charge states, and they made use of the fact that, on an average, for each L-ghell electron removed between charge states Fe XVII to Fe XXV, the 1s-2p $\mathrm{X}$-ray energy increased by an amount of $40 \mathrm{ev}$. Flgure 4 shows the $K \alpha-1$ ine spectra obtained for different electron temperatures. Evidently the intensity is shifted to higher states of lonization with insreasing electron temperature. For $T_{e}(0) \geq 1.2 \mathrm{keV}$, iron occurs predominatly in the helium- and lithium-like charge states. A detalled comparison of these experimental results with calculations by Merts et al., ${ }^{24}$ showed that the distribution of the lower charge states was in reasonable agreement with coronal equilibrium predictions. Substantial deviations from coronal equilibrium were found for Ee XXV, however. These deviations can be explained by an outward radial transport of $\mathrm{Fe} \mathrm{XXV}$ ions on the basis of the fact that the transport time for these tons is small compared to the relevant lonfzation and recombination 
times. In general, the observed devlations from coronal equilibrium become smaller with increasing electron density. 27 The assignment of intensity pears (in Fig. 4) to individual states of ionization gives a simplified picture, since the spectral ranges from neighboring charge states overlap to some extent. However, the spectral lines of the two and three electron systems, e.g., Fe XXV and Fe XXIV, are well resolved. This is important for diagnostic applications.

Figure 5 shows the calculated intensity $\left[\right.$ in photons $\left./\left(\mathrm{cm}^{3} \mathrm{sec}\right)\right]$ for the 1s-2p transition of $F e x X$ as a function of plasma radius for different central electron temperatures assuming parabolic radial electron temperature and density proflles, and coronal equlibrium for the Fe $x x V$-ions. Due to the strong variation of the excitation rate with electron temperature, the Fe XXV Ko-resonance line is predominantly emitted from the center of the discharge, for $\mathrm{T}_{\mathrm{e}}(0)=1-4 \mathrm{kev}$. For this range of electron temperatures, the observed line spectra of $\mathrm{Fe} X X V$ can be used directly as a diagnostic of the central plasma parameters. For higher central electron temperatures the helium-like charge state is burned out in the core of the discharge, so that the emissivity for the $K \alpha$-resonance line is peaked at the outer plasma radii. Under these conditions, the central plasma parameters can be obtained from observations along different radial chords using Abel inversion.

IV. CRYSTAL SPECTROMETERS

In this section we describe the crystal spectrometers which have been used on PLT and PDX for observation of the satellite spectriz of helium-like iron (Fe XXV) and titanium (Ti XXI). These experlments demanded optimization of the spectrometer design for (1) gimultaneous observation of different spectral lines, (2) high spectral lesolution, and (3) high Intengity to enable 
time resolved measurements. These requirements led to the cholce of focusing bent crystal spectrometers with a position sensitive detector in the Johann configuration. 28

\section{Experimencal Arrangement}

A schematic of a Johann crystal spectrometer and its arrangement on a tokamak is shown in Fig. 6. X-ray photons emitted along chords in the horizontal midplane from impurity ions in the shaded area of the tokamak discharge enter helfum filled pipes through a $0.003^{\prime \prime}$ thick beryllium window and are Bragg reflected by the crystal onto a position sensitive multiwire proportional counter. Photons of different energies are focused to different points on the Rowland circle and thus to different positions on the detector. The helium atmosphere in the $\mathrm{x}$-ray path reduces photon absorptio.1. The detector has two planes of approximately 100 anode and cathode wires w1th 1 mon separation running perpendicular to sach other, as 1llustrated in Fig. 7. An $\mathrm{X}$-ray photon lonizes the Pto gas mixture (908 argon +108 methane) inside the detector producing an electron avalanche to one of the anode wires. This charge pulse induces an inage charge 0.1 the cathode wires which is capacitively coupled to a delay line. Standard electronics are used to convert the difference in the arrival times of the charge pulse at the two ends of the delay line Into a pulse, whose amplitude is proportional to the position at which the photon struck the detector. These pulses are digitized, stored in the memory of a pulse-height analyzer, and later read by a PDP10 computer.

Since the experiments were performed in an environment with high levels of hard $x$-ray and neutron background radiation, the detector had to be shlelded. Lead (4" thlck) was used to shield the detector against the hard $x-$ 
ray radiation. Since the $2.5 \mathrm{MeV}$ neutrons emittea from the plasma produce $(n, \gamma)$-reactions in the lead shielding, it has been enclosed by a ( 8 " thick) neutron shield of borated (58 Boron) polyethylene. This shielding permilted recording of soft $x$-ray spectra fron deuterium plasmas also during injection of intense (6-8 MW) deuterium beams when the neutron emission from $D-D$ rezctions was particularly high, typically about $10^{14}$ neutrons/sec, corresponding to a flux of $10^{8}$ neutrons/(cm $\left.\mathrm{cm}^{2} \mathrm{sec}\right)$ at the position of the detector.

\section{Spectral Resolution}

Following Bragg's law

$$
\lambda=2 \alpha \sin A
$$

where $\lambda, a$, and $\theta$ are the wavelength of the $x$-ray photon, the spacing of the reflecting crystal planes, and the Bragg angle, respectively, the dispersion of a crystal spectrometer is given by

$$
\frac{\lambda}{\Delta \lambda}=\frac{1}{\Delta \theta} \tan \Theta
$$

The angular -esolution $(\Delta A)$ is mainly determined by the spatial resolution $(\Delta x)$ of the detector and the crystal-detector distance (D). For the Johann configuration, $D=R \sin \theta$, where $R=2 r$ is the radius of curvature of the crystal, and $r$ is the radius of the Rowland cirule. According to Eq. (3) it is advantageous to choose a crystal such that the Bragg angle, $\theta$, is ciose to 90 degrees. 
The spectral resolution can further depend on the intrinsic resolving power of the crystal and on geometrical effects, (1) the specific focusing error of the Jchann conflguration due to the fact that the crystal surface is tangential to the Rowland circle only at one polnt, and, more importantly, (2) errors due to the vertical divergence (w1th respect to the spectroineter plane) of $x$-ray beans. The Johann aberration $(\Delta)$ is given by $\Delta=l^{2} \cos \theta /\left(8 R \sin ^{2} \theta\right)$, where $\ell$ is the length of the crystal. Evidently both the Johann defocusing ( $\Delta)$ ind the focusing errors due to the vertical alvergence decrease with increasing Bragg angle $(\theta)$ and radius $(R)$ of crystal curvature. Since the mosaic spread of a crystal is known to increase occastonally in the bending process, we chose quartz crystals with a very high intrinsic resolving power $>100000$

In practice, the spectral resolution is limited mostly by the finite spatial resolution of the detector. Its yositloning in the Rowland circle is therpfore very important. The spatial resolution of the used multiwlre proportional counters is .37 Tm FWHM for perpendicular incidence of the photons. Therefore, the detector is not placed tangential to the Rowland circle but perpendicular to the reflected beam. This 1.5 necessary because the thickness $(2 \mathrm{~cm})$ of the sensitive detection volume is relatively large. The focusing error resulting from the displacement of the detector from the Rowland wecle decreages with increasing $\theta$, another reason for choosing a large Bragg angle. For the high resolutior crystal spectrometers which we used for Doppler broadening measurements, the displacement of the detector fron the Rowland circle was comparable with the detector thickness. Optimum focusing can thus be obtained over a small energy interval. However, even for this limited energy range the resolution is afferted by the finite thickness of the counter due to the vertical divergence of the reflected beams. It is, 
of course, very important to properly align the anode and cathode wires with respect to the directions of the incident photons. This has to be optimized by rotating the detector.

The energy resolution of the crystal spectrometers has been determined experimentally by use of appropriate X-ray lire:s, after the crystals had been bent to the desired radius of curvature applying the method described by Feger and Faesslex. 29 Here we mainly discuss the results obtained for the $(22 \overline{4} \overline{3})$ quartz rystal spectrometer mich was used for measurements of the Fe XXV spectra. The crystal was bent to a radius of curvature of $333 \mathrm{~cm}$. To determine the energy resolution of this crystal we used the $L \alpha_{1}$ and $L \alpha_{2} l$ ines of Holmium (at. $6720 \mathrm{eV}$ and $6680 \mathrm{eV}$ ) which are close in energy to the Fe XXV $\mathrm{Ka}$ - resonance line at $5702 \mathrm{eV}$. Since the natural line width of the Holmtum iines is about $6 \mathrm{ev}$, a special arrangement had to be made to measure the much smaller instrumental width of the spectrometex. A narrow .381 min $\left(.015^{\prime \prime}\right)$ wide slit was placed exactly on the Rowland circle at the focal point for the Holmium La, line. In this way only a small central portion of the La, -1 ine is Bragg reflected and focused onto the detector. Figure sa shows the results of this measurement. The experimental poincs represent an image of the slit which is well approximated by a Gaussian $\left(G_{p}\right)$ of $.497 \mathrm{~mm}$ EWHM. Following Unsold ${ }^{30}$ we describe the slit by a Gausgian $\left(G_{s}\right)$ of a FWHM $=2 a[(\ln 2) / 6)^{1 / 2}$. rhere $a$ is the width of the slit, and assume that the image is the result of a convolution with a Gaussian instrumental function ( $\left.G_{I}\right)$. We obtain a value of $.424 \mathrm{~mm}$ for the width (FWHM) of the instrumental function. This corresponds to an energy resolution of $\Delta E=.420 \mathrm{ev}$ at $\mathrm{E}=6700 \mathrm{ev}$, or $\mathrm{E} / \Delta \mathrm{E}=15000$.

Also shown in Fig. $8 b$ are the resilts of a measurement of the spatial resolution of the position sensitive detector. For this purpose a collimated $\mathrm{Fe}^{55}$ line source (of approximately zero width) was placed directly on the 
entrance window of the detector. The collimation was obtained by close contact of two tool bits. The experimental points in Fig. $8 \mathrm{~b}$ are well approximated by a Gaugsian with .369 $\mathrm{mm}$ FWHM. This shows that the instrumental width is mogtly determined by the firite spatial resolution of the detector.

The energy resolution of the $20 \overline{2} \overline{3}$ quartz crystal, which was used for Doppler broadening measurements of the $T 1$ XXI Kx-line at $4.75 \mathrm{keV}$, has been determined by the same experimental method, except that, in this case, the measurements were performed with the second order Bragg reflection of the tungsten $L f,-l i n e$ at $9.670 \mathrm{kev.} \mathrm{For} \mathrm{this} \mathrm{crystal,} \mathrm{which} \mathrm{was} \mathrm{bent} \mathrm{to} \mathrm{a} \mathrm{radius}$ of curvature of $363.5 \mathrm{~cm}$, the obtained spectral resolution $(\lambda / \Delta \lambda)$ was 23000 .

\section{Intensity}

Estimates of the $X-r a y$ line intengities as recelved by the deuctor from a PLT or PDX alscharge have been obtained from an $x$-ray tracing code for the experimental parameters (1.e., the size of the crystal, the dimensions of the detector window and the beryllium window on the tokamak vacuum vesgel, and the distances of the cryatal from thege windows/. Here we consider. the basic aspects. Since the tokamak plasma is an extended X-ray source, the intensity 1s, In prinsiple, independent of the distance of the crystal from the plasma, provided that each crystal element views the plasma with a solid angle which is larger than the width of its rocking curve $\partial^{\text {t }}$ ine considered Bragg angle. In practice, however, the intensity varies with the alstance of the crystal from the plasma in proportion to the vertical divergence of the detected $x$ rays which is usually limited by the height of the beryllium window on the tokamak vacuim vessel. On the other hand, as mentioned before, a limitation of the vertical divergence may be desirable to reduce focusing ercoro. The 
Intensity also depends on Bragg angle $A$. For perfect crystals like quartz, the integrated reflectivity increases strongly with $A$, if $A>45$ degrees. It is worth mentioning that the spatial resolution of multiwire proportional counters often deteriorates at very high photon count rates because of space charge effects near the anode wires. This sets an upper limit for the acceptable photon intensities $(20,000$ counts/sec for our detectors). Because of this count rate limitation we had to reduce the $x$-ray intensity in certain cases by shielding parts of the crystal. Finally, we mention that the focal points of spectral lines must not fall into the plane of the beryllium window, in order to prevent the observed line intensities being affected by inhomogeneities of the window transmission.

\footnotetext{
V. EVALUATTIN OF LINE PROFILES

The profile of a spectial line is described by a voigt-function, which is the convolution of a Lorentzian and a Gaussian. T'ie Lorentzian describes the natural line broadening, whereas the Gaussian accounts for the Doppler broadening of the spectral line due to the thermal ton motion. This is by far the dominant line broadening mechanism in hot tokamak plasmas. Since the Doppler width is usually large compared with the natural line width, the upper part of the voigt profile is determined mainly by the Gaussian; whereas, because of exponential decay of the Gaussian, the lower part of the voigt profile, i.e., the wings, is determined by the Iorentzian.

The ion temperature is, therifore, often evaluated from the fit of a raussian to the upper half of the observed line profile. Though this method yields, in principle, a reasonable value for the lon temperature, tie statistical error can be rather large because only a limited number of the experimental point:s are actually used for the $f 1 t$, and valuable 1nformation in
} 
the wings of the observed line profile is ignored, in practice, longer recording times are required if the statistical error is to be reduced to a certain limit. For time resolved measurements it is therefore advantageous to fit the observed spectral lines to actual volgt-profiles.

For the calculation of Volgt-profiles it is convenient to make use of the close relationship between the Voigt-function and the so-called Plasma Dispersion Function,

$$
z(\xi)=\frac{1}{\sqrt{\pi}} \int_{-\infty}^{\infty} \text { dt } \frac{\exp \left(-t^{2}\right)}{t-\xi}
$$

where $\xi=x+1 y$, with $y=\operatorname{Im} \xi>0$, is a complex variable. The 2mennction 1 s of basic Importance in the phystis of plasma waves and has been extensively studied. The function has been tabulated by Fried and conte ${ }^{31}$ and several codes for 1 ts computation are available. Introducing $\xi=x+1 y$ into Eq. (4) one obtains for the Imaginary part of $z(x, y)$

$$
\operatorname{In} z(x, y)=\frac{1}{\sqrt{\pi}} \int_{-\infty}^{\infty} a t \exp \left(-t^{2}\right) \frac{y}{(t-x)^{2}+y^{2}}
$$

with

$$
\frac{1}{\pi} \int_{-\infty}^{\infty} \operatorname{Im} z(x, y) d x=1
$$

The Voigt-function is thus most conveniently represented in che form 


$$
V(x, y)=\frac{A}{\pi} \operatorname{Im} Z\{x, y),
$$

with

$$
x=\frac{\omega-\omega_{0}}{\omega_{0}} \frac{c}{v_{1}} \text { * and } y=\frac{y / 2}{\omega_{0}} \frac{c}{v_{1}}
$$

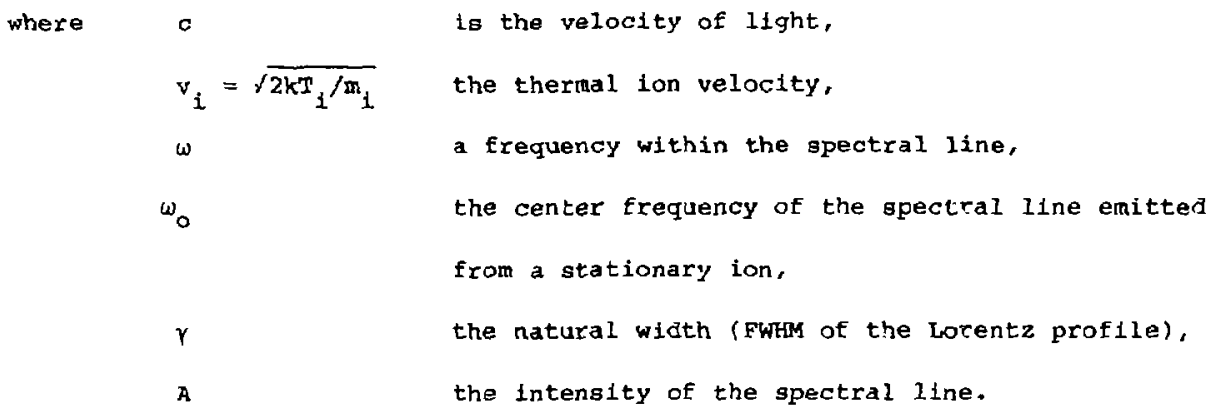$$
\omega
$$$$
\omega_{0}
$$$$
\text { a frequency within the spectral line, }
$$$$
\text { the center frequency of the spectral Ine enitted }
$$$$
\text { from a stationary ion, }
$$

$\gamma$ the natural width (FWHM of the Lorentz profile), the Intensity of the spectral line.

\footnotetext{
* The variable $x$ represents the ratio of the lon velocity ( $v$ ) and the thermal ion velocity $\left(v_{i}\right)$

In order to determire the characterlstic line parameters, e.g., the center frequency $\omega_{0}$ and the thermal fon velocity $v_{1}$, from a least squares fit, one needs the partial derivatives of the voigt-function with respect to $x$ and $y$ - These derivatives are easily obtained with use of a differential equation for $z^{\prime}\left(F_{,}\right):$
}

$$
Z^{\prime}(F)=-2[1+F, Z(F,)]
$$


One obtains

$$
\frac{\partial}{\partial x} \operatorname{Im} z(x, y)=\operatorname{In} z^{\prime}(F,)
$$

and

$$
\frac{\partial}{\partial y} \operatorname{Im} z(x, y)=\operatorname{Re} z^{\prime}(F)
$$

It is therefore sufflclent to calculate only the real and imaginary parts of 7 . Our line fltting program uses the Eqs. (6)-(9) to find values of A, $\omega_{0}, \gamma / 2$ and $v_{i}$, whlch minimize $\chi^{2}$, given by

$$
\chi^{2}=\sum_{\ell}^{M} \frac{1}{\sigma_{\ell}^{2}}\left[D_{\ell}-\sum_{p=1}^{4} \mathrm{~A} v\left(\omega_{o p}, \gamma_{p / 2}, v_{i}, l\right)-B\right]^{2},
$$

where $D_{l}$ is the raw data in the lth position, $\sigma_{l}$ is the error, $v$ is the Voigtfunction, and $B$ is a constant background. The program allows us to fit up to $p=4$ peaks in a certair spectral regiol, :imultaneously. 
VI. EXPERIMENTAL RESULTS

In this section wa present spectra of helium-1ike iron (Fe $\mathrm{xXV}$ ) and titanium ( $T i$ XXI) and discuss their Aiagnostlc applications for electron and ion temperature measurements in tokamak discharges. Spectra of Fe xxv have been studied on PLT for a wide variety of plasma conditions during the last few years, and these data have permitted a detalled comparison between experiment ${ }^{10,18}$ and theory. $9,15-17$ Here we include some of the experimental results to discuss the characteristic spectral features of helfum-1ike ions, in particular, the electron temperature dependence of intensity ratios. Special emphasis is given to recent results of Doppler-broadening measurements of the $\mathrm{Ti} X X I \mathrm{~K} x$-resonance line which allowed determination of the central ion temperature in PDX tokamak discharges with additlonal neutral beam heating.

The most characteristic feature of the specira emitted from helium-like ions in hot plasmas is the oncurrence of satelittes to the $(1 \mathrm{~s}-2 \mathrm{p})$ resonance 1ine. These satellites are due to transitions of the type $1 \mathrm{~s} 2 \mathrm{pn} \ell-1 \mathrm{~s}^{2} \mathrm{n} \ell$ (with $n \geq 2$ ), which represent the flnal step in the process of dielectronic recombination of a helium-like ion. Here we give a brief description of this atomic process. It can be the dominant mechanism of line excltation in hot plasmas and is thus very important for the interpretation and diagnostic application of the observed spectra.

The lithium-like configurations are produced by the process

$$
1 s^{2}+e+1 s 2 p n l
$$

A free electron of well defined kinetic energy and angular momentim is captured by a hellum-like ion 1nto an atomlc level with quancum numbers $n, l$ to form an excited lithlum-like 1on. The 1s2pnl levels are virtually bound 
states located in the continuum above the first ionization limit of the Iithium-Iike ton. They can, therefore, decay by autolonization, the reverse process of capture, or by a radiative transition to the $1 s^{2} \mathrm{n} s$ level. In the latter case, the $18-2 p$ transition is slightly changed in energy by the presence of the "spectator" $(n, l)$ electron in the outer shell, so that the emitted photon gives rise to a satelifte near the $1 \mathrm{~s}-2 \mathrm{p}$ resonance line of the helium-like ion. The wavelength shift of the satellites depends on the main quantum number $n$ of the captured outer shell electron. The $n=2$ dielectronic satellites are well resolved. However, satellites with $n \geq 3$ are very close to and partially blended with the resonance line.

The unresolved $n \geq 3$ satellites cause an apparent intensity increase and broadening of the resonance line. These effects, which are pecullax to hot plasmas, must be taken into account for evaluation of satellite to resonance line ratios and Doppler broadering measurements. A detailed thecry of the diclectronic satelites with $n=3-11$ of the resonance line of Fe XXV has beer glven recently by Bely-Dubau et a.t. ${ }^{9}$ and comparison of this theory with experiment was made by Bitter et al. ${ }^{10}$ Both the apparent Intensity Increase and the dielectronic broadening of the resonance line are very sensitive to the electron temperature.

since the process of dielectronlc capture Involves electrons with well defined kinetic energles $(\varepsilon=4.694 \mathrm{keV}$ for $\mathrm{n}=2$ and $\varepsilon=5.815 \mathrm{keV}$ for $n=3$ in Fe $\mathrm{XXV}$ ), the satelite Intensities are dependent on the energy diatribution of the electrons in the plasma and proportional to the abundance of the heliumlike ions. The resonance lines are excited by electrons with energies larger than the $1 \mathrm{~s}-2 \mathrm{p}$ threshold energles $\left(6.7 \mathrm{kev}\right.$ for $\mathrm{Fe} \mathrm{xXV}$ ). The rattos ( $\mathrm{I}_{\mathrm{s}} / \mathrm{I}_{\mathrm{w}}$ ) of the intensities of the dielectronlo sateliftes and the resonance line are consequently a function of the electron temperature ( $T_{e}$ ) alone, given by 15 


$$
\frac{I_{S}}{I_{w}}=D \frac{\exp \left(\Delta E / T_{e}\right)}{T_{e}}
$$

where $\Delta E$ is the Ionization energy needed to remove the outer $(n, l)$ electron, and $D$ is a constant mainly determined by the branching ratio of the probabilities for autoionization and radiative decay of the excited lithiumlike ion.

Most of the satellites are produced by the described process of dielectronic recombination. Exceptions are the $\left(1 s^{2} 2 s-1 s 2 p 2 s\right)$ satellites which can also be produced by collisional innex shell excitation of a litivinlike ion in its ground state. For these satellites the intensity ratio $\left(I_{s} / I_{w}\right)$ is proportional to the relative abundance $\left(n_{L i} / n_{H e}\right)$ of the lithiumand helium-like charge states,

$$
\frac{I_{s}}{I_{w}}=s \frac{n_{L_{i}}}{n_{\text {He }}},
$$

where $\mathrm{S}$ ig essentially given by the ratio of the oscillator strengths for the $1 s-2 p$ transitions, e.g., of Fe XXIV and Fe XXV. ${ }^{15}$

Figures $\varphi(a)$ and $\varphi(b)$ show satellite spectra of Fe $x X V$ obtained for central electron temperatures of 1.65 and $2.30 \mathrm{kev}$, respectively. The spectra have been observed on PLT using the $(22 \overline{4} \overline{3})$-quartz cryatal spectrometer with a resolution of $\lambda / \Delta \lambda=15000$. The electron temperature was deternined from the electron-cyclotron radiation emltted by the plasma. ${ }^{32}$ The raw data for each 
of these spectra were recorded during a perfod of $250 \mathrm{msec}$ of a discharge pulse when the electron temperature was constant (steady-state conditions) and were accumulated typlcally over ten discharges with nearly identical parameters to reduce the statistical error. The center position, intensity, and width of the spectral lines were determined from a least squares $f 1 t$ of voigt-functions as described in section $v$. In order to determine these line parameters with minimum errot, it was necessary to fit groups usually of two neighboring peaks simultaneously. The most prominent peaks have been identified as the helium-like lines $w, x, y, z$, the lithium-like $n=2$ satellites $t, q,(k, x), j$, and the beryllium-like line $R$. The key letters used for line identification are explained in Table $I$ and agree with Gabriel's notation. 15 The spectra also show a fine line structure between some of the most prominent peaks and on the long-wavelength side of the resonance line w. This ztructure disappe.ses with increasing electron temperature and is ascribed to weak $n=2$ satellites, such as $a$, and to $n=3$ satellites, respectively. 
Table I.

Experimental and theore ical wavelengths of the observed FexxV spectral lines. The superscripts indicate the references from which the theoretical wavelengths were taken. The experimental wavelengths were normalized to the theoretical value (Ref. 15) of 1.8500 \& for the regonance IIne $w$.

\begin{tabular}{|c|c|c|c|}
\hline (key) & Transition & $\begin{array}{l}\lambda_{\exp } \\
\text { (A) }\end{array}$ & $\begin{array}{l}\lambda_{\text {theor }} \\
\text { (A) }\end{array}$ \\
\hline$w$ & $1 s^{2}\left({ }^{1} s_{0}\right)-1 s 2 p\left({ }^{1} p_{1}^{\circ}\right)$ & 1.8500 & $\begin{array}{l}1.8500^{\mathrm{a}} \\
1.84992^{\mathrm{b}}\end{array}$ \\
\hline $\mathrm{x}$ & $1 s^{2}\left(s_{0}\right)-1 s 2 p\left({ }^{3} P_{2}^{0}\right)$ & 1.8552 & $\begin{array}{l}1.8551^{\mathrm{a}} \\
1.85519^{\mathrm{b}}\end{array}$ \\
\hline$t$ & $1 s^{2} 2 s\left({ }^{2} s_{1 / 2}\right)-1 s 2 p 2 s\left({ }^{2} P_{1 / 2}^{0}\right)$ & 1.8567 & 1.8570 \\
\hline$Y$ & $1 s^{2}\left(s_{0}\right)-i s 2 p\left({ }^{3} p_{1}^{0}\right)$ & 1.8592 & $\begin{array}{l}1.8591^{\mathrm{a}} \\
1.85947^{\mathrm{b}}\end{array}$ \\
\hline$q$ & $1 s^{2} 2 s\left({ }^{2} s_{1 / 2}\right)-1 s 2 p 2 s\left({ }^{2} p_{3 / 2}^{\circ}\right)$ & 1.8608 & $1.8604^{\mathrm{c}}$ \\
\hline a & $1 s^{2} 2 p\left({ }^{2} p_{3 / 2}^{0}\right)-1 s 2 p^{2}\left({ }^{2} p_{3 / 2}\right)$ & 1.8618 & $1.8618^{\mathrm{a}}$ \\
\hline $\begin{array}{l}\mathrm{k} \\
\mathrm{r}\end{array}$ & $\begin{array}{l}1 s^{2} 2 p\left({ }^{2} p_{1 / 2}^{\circ}\right)-1 s 2 p^{2}\left({ }^{2} D_{32 /}\right) \\
1 s^{2} 2 s\left({ }^{2} s_{1 / 2}\right)-1 s 2 p 2 s\left({ }^{2} p_{1 / 2}^{\circ}\right)\end{array}$ & 1.8632 & $\begin{array}{l}1.8631^{a} \\
1.8635^{a}\end{array}$ \\
\hline$j$ & $1 s^{2} 2 p\left({ }^{2} p_{3 / 2}^{O}\right)-1 s 2 p^{2}\left({ }^{2} D_{5 / 2}\right)$ & 1.8657 & $1.8657^{a}$ \\
\hline$z$ & $1 s^{2}\left({ }^{1} s_{0}\right)-1 s 2 s\left({ }^{3} s_{1}\right)$ & 1.8681 & $\begin{array}{l}1.8677^{a} \\
1.86807^{b}\end{array}$ \\
\hline 日 & $1 s^{2} 2 s^{2}\left({ }^{1} s_{0}\right)-1 s 2 s^{2} 2 p\left({ }^{1} v_{1}\right)$ & 1.8705 & $1.8710^{\mathrm{C}}$ \\
\hline$a_{\text {Ref. }} 15$ & $b_{\text {Ref. } 33}$ & $c_{\text {Ref. } 34}$ & \\
\hline
\end{tabular}


Experimental and theoretical wavelengths are listed in Table $I$ for comparison. For most of the lines the agreement is within the estimated error of $0.0005 \&$ of the theoretical calculations. The experimental accuracy is $0.0009 \AA$.

of great interest for diagnosic applicitions are the sateliftes $f$ and q. The satellite $j$ is produced by dielectronic recombination. According to Eq. (11) the intensity ratio $\left(I_{j} / I_{w}\right)$ can thus be used as a diagnostic for the electron temperature. The atellite $q$, on the other hand, is produced by collisional inner shell excitation so that, according to Eq. (12), intensity ratio $\left(I_{q} / I_{w}\right)$ can be used for a measurement of the relative abundance ( $\mathrm{n}_{\mathrm{Li}} / \mathrm{n}_{\mathrm{He}}$ ) of the lithium- and helium-like lons.

Figuere 10 presents the experimental results for $I_{j} / T_{w}$ together with predictions of the earlier theory ${ }^{15,16}$ (solid curve) and the most recent theory ${ }^{9}$ (dashed curve) for the experimental valuss of $T_{e}$. The theory of BelyDubau et al. 9 takes into account the apparent intensity increase, $\Delta I_{w}=$ $\alpha\left(T_{e}\right) I_{w}$, of the resonance line due to unresolved dielectronic satellites with $n \geq 3$. The experimental results shown in Fig. 10 are in excellent agreenent with the most recent theoretical predictions, 9 indicating that the satellite to resonance line ratio $\left(I_{j} / I_{w}\right)$ can be used as a diagnostic of the central electron temperature.

on the other hand, the relative abundance $\left(\pi_{\mathrm{Fe}} \times \mathrm{xIV}^{/ / \pi_{\mathrm{Fe}}} \mathrm{xxV}\right)$ of the lithium- and helium-11ke charge states derived from the lntensity ratio ( $I_{q}\left(I_{w}\right)$ are found to deviate sigiflcantly (up to factors of five) from the predictions for coronal equilibrium. These deviations are observed to depend, in particular, on the electron denstty. They are ascribed to changes of the charge-state distribution due to impurity transport, whlch is disregarded in the model of coronal equilibrium. Experimentally one finds that coronal equilibrtum 1s approached wth increasing plasma density. 27 
The experimental result that the relative intensities of the aielectronic satelites and the resonance Ilne are in good agreement with the theoretical predictions is explained by the fact that these lines involve oniy the helium-like charge state, Fe $x \times v$. Their intensity ratios are thus independent of the details of the Ionlzation equilibrium or impurity transport and are uniquely determined by the electron temperature. Thersfore, it has been possible to measure the dielectronlc recomblnation rate coefficient of

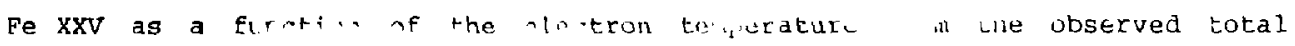
intensity of the dielectronic satellites. 35

In the following we present the ion-temperature results which have been obtained Irom Doppler-broadening measurements of the Ti XXI Ka - resonance Iine. The eiperiments were performed on PDX using the $(20 \overrightarrow{2} \overline{3})-q u a r t z$ crystal spectrometer with a resolution of $\lambda / \Delta \lambda=23000$. Figure 19 shows the 1 ine spectrum of $\mathrm{Ti} X X I$ as nbserved from ohmically heated PDX discharges with central electron temperatures of $\approx 1 \mathrm{keV}$. The data were accumulated from approximately ten discharges with similar parameters. The spectrum shows the Ti XXI $\mathrm{K} \alpha$-resonance line (1), the characteristic helium-like intercombination lines (5) and (8), and a series of delectronic satellites due to transitions of the type $15^{2} n l-1 s 2 p n l$ with $n \geq 2$. The spectrai features have been identified vith use of the theoretical predictions of Gabriel, 36 vainshtein and Safxonova, ${ }^{17}$ and Ermolaev and Jones, ${ }^{33}$ and are explained in Table II.

Figures 12 and 13 show the results obtained from Doppler broadening measurements of the Ti XXI $\mathrm{K} \alpha$-resonance Iine. The data have been obtained from PDX discharges with additional neutral beam herting. Four deuterium beams totaling a power of $5 \mathrm{MW}(47 \mathrm{kV})$ were injected into hydrogen discharges with a line averaged density of $4 \times 10^{13} \mathrm{~cm}^{-3}$ for the period from $300-450$ msec. Figure 12 shows a time sequence of $\mathrm{s}$. 
which have been recorded from each discharge with a time resolution of $25 \mathrm{msec}$. The data have been accumulated from 20 discharges with nearly identlcal parameters to reduce the statistical error. The solid curves were obtained from a least squares fit of Voigt-functions to ttic sxperimental data as described in Section $v$. The arrows 1ndlcate the range of channels used for the fit. The average in the channels below the lower limit was used for background subtraction. The upper limit was chosen to exclude the $n=3$ satellites. An enhanced line broadening during neutral beam injection is evident from Fig. 12 .

Figure 13 presents the ion-temperature results, deduced from the experimental line profiles, as a function of time. The error bars indicate the statistical error of the experimental results. Corrections are made for the rlatural line width and the instrumental width. Errors due to the dielectronic lire broadening by unresolved $n \geq 3$ satellites have been Alsiussed in detall in Ref. 10. These exrors are determined by the electron temperature (which was in the range from 1 to $2 \mathrm{keV}$ for these experiments) and are estimated to be less than 58. Also shown in Fig. 13 are the results (triangles) from measurements of the energy distribution charge-exchange neutrals (hydrogen atoms) which are in very good agreement with the Doppler ion temperatures. 
Table II.

Experimental and theoretical wavelengths of the observed TixxI spectral lines. The superscripts indicate the references from which the theoretical wavelengths were taken. The experimental wavelengths were normalized to the treoretival value (Ref. 36 ; of 2.6099 A for the resonance line $w$.

\begin{tabular}{|c|c|c|c|c|}
\hline Peak & (key) & Trangition & $\begin{array}{l}\lambda \exp \\
(\Omega) \\
\end{array}$ & $\begin{array}{c}\lambda \text { theor } \\
\text { (A) } \\
\end{array}$ \\
\hline \multirow[t]{3}{*}{1} & $w$ & $1 s^{2}\left({ }^{1} s_{0}\right)-1 s 2 p\left({ }^{1} P_{1}^{0}\right)$ & 2.6099 & $2.6099^{\pi}$ \\
\hline & & & & $2.6097^{\mathrm{b}}$ \\
\hline & & & & $2.61018^{\circ}$ \\
\hline 2 & & & 2.6117 & \\
\hline 3 & & & 2.6134 & \\
\hline 4 & d13 & $\begin{array}{l}1 s^{2} 3 p\left(^{2} p_{3 / 2}\right)- \\
1 s^{2} p 3 p\left({ }^{2} D_{5 / 2}\right)\end{array}$ & 2.6142 & \\
\hline \multirow[t]{2}{*}{5} & $\mathbf{x}$ & $1 s^{2}\left({ }^{1} s_{a}\right)-1 s 2 p\left({ }^{3} p_{2}^{0}\right)$ & 2.6184 & $2.6187^{\mathrm{a}}$ \\
\hline & & & & $2.6183^{b}$ \\
\hline \multirow[t]{2}{*}{6} & s & $1 s^{2} 2 s\left({ }^{2} s_{1 / 2}\right)-$ & 2.6195 & $2.6207^{a}$ \\
\hline & & $1 \mathrm{~s} 2 \mathrm{p}\left({ }^{3} p\right) 2 \mathrm{~s}^{2}\left(^{2} \mathrm{p}_{3 / 2}\right)$ & & $2.6197^{b}$ \\
\hline \multirow[t]{2}{*}{7} & $t$ & $1 s^{2} 2 s\left({ }^{2} s_{1 / 2}\right)-$ & 2.6205 & $2 \cdot 6 \cdot 214^{\mathrm{a}}$ \\
\hline & & $\left.1 s^{2} p^{2} s^{2} t_{1 / 2}\right)$ & & $2.6205^{b}$ \\
\hline \multirow[t]{3}{*}{8} & $y$ & $1 s^{2}\left({ }^{1} s_{o}\right)-1 s 2 p\left({ }^{3} P_{i}^{0}\right)$ & 2.6223 & $2.6226^{a}$ \\
\hline & & & & $2.0221^{b}$ \\
\hline & & & & $2.62266^{\mathrm{C}}$ \\
\hline \multirow[t]{3}{*}{9} & $q$ & $\begin{array}{l}1 s^{2} 2 s\left(^{2} s_{162}\right)- \\
1 s 2 p 2 s\left({ }_{p}^{3}{ }_{3 / 2}\right)\end{array}$ & 2.6271 & $2.6272^{b}$ \\
\hline & a & $1 \mathrm{~s}^{2} 2 \mathrm{p}\left({ }^{2} \mathrm{P}_{3 / 2}^{\circ}\right)-$ & & $2.6295^{a}$ \\
\hline & & $1 \mathrm{~s} 2 \mathrm{p}^{2}\left({ }^{2} \mathrm{p}_{3 / 2}\right)$ & & $2.6296^{b}$ \\
\hline \multirow[t]{4}{*}{10} & d & $1 s^{2} 2 p\left({ }^{2} p_{1 / 2}^{0}\right)-$ & & $2.6297^{\mathrm{a}}$ \\
\hline & & $1 s 2 p 2 s\left({ }^{2} P_{1 / 2}\right)$ & 2.6294 & $2.6299^{b}$ \\
\hline & $r$ & $1 s^{2} 23\left({ }^{2} s_{1 / 2}\right)-$ & & $2.6299^{a}$ \\
\hline & & $1 s 2 p 2 s\left({ }^{2} P_{1 / 2}\right)$ & & $2.6295^{b}$ \\
\hline \multirow[t]{3}{*}{11} & $k$ & $1 \mathrm{~s}^{2} 2 \mathrm{p} \mathrm{t}^{2} \mathrm{P}_{1 / 2}{ }^{j}-$ & 2.6311 & $2.6326^{\mathrm{a}}$ \\
\hline & & $1 s 2 p^{2}\left({ }^{2} D_{3 / 2}\right)$ & $(z)$ & $2.6314^{b}$ \\
\hline & 36 & $b_{\text {Ref. }} 17$ & $c_{\text {Rei. }} 33$ & \\
\hline
\end{tabular}


In principle, the impurity ion temperature can differ from the temperature of the bulk ion species. An estimate of the expected ion temperature difference can be owtained from a calculation due to R. Soldston: ${ }^{1}$ The power coupled from the beam lons to each fon species in the plasma is proportional to $\mathrm{n}_{1} \mathrm{z}_{1}^{2} / \mathrm{mi}$. Thug, while the total power delivered io impurity ions may be small, the power per ion scales as $z_{i}^{2} / \mathrm{mi}$. At low densities and high ion temperatures, the impurity-hydrogen coupling time becomes long enough so that a temperature difference should develop between the impurity ions and the hydrogenic species. For low-density cases where $z_{\text {eff }}=3$, due primarily to carbon, all of the Impurity lons are well coupled to each other, and one may write a simpl equation governing the impurity temperature, $\mathbf{T}_{\mathbf{x}}$ :

$$
\frac{d T_{x}}{d t}=0=\frac{T_{H}-T_{x}}{\tau_{x-H}}+\left.\frac{d I^{\prime}}{d t}\right|_{\text {bean }}+\frac{T_{e}-T_{x}}{\tau_{x-e}}-\frac{r_{x}}{\tau_{E x}},
$$

where $\tau_{x-H}$ and $\tau_{x-e}$ are the energy equilibrium times between the impurities and the hydrogenic species, and between the impurities and electrons, respectively. $\tau_{\mathrm{Ex}}$ is the energy containment time of the impurities.

Taking the dominant impurity to be carbon, and solving this equation for simflar parameters of a neutral beam heating experiment on PLT, Goldston found a temperature difference of $T_{x}-T_{H}=800 \mathrm{ev}$, assuming a bulk (hydrogen) lon temperature of $T_{H}=5 \mathrm{keV}$. The evaluation of $T_{X}-T_{H}$ is uncertain to within a factor of 2 ; the possible temperature differential drops dramatically, however, as the density increases and especially as the ion temperature decreases. 1 Experimentally we find that for the parameters of the PDx 
experiment the ion temperature differences $T_{x}-T_{H}$ are $w$ ithin the error bar (Fig. 13). Note that the charge-exchange diagnostics is still able to determine the central icn temperature for plasma dengities of $4 \times 10^{13} \mathrm{~cm}^{-3}$ and plasma radii of $40 \mathrm{~cm}$.

The line profiles in Fig. 12 also show a Doppler shift in addition to the line broadening. Figure 14 presents the observed line shifts as a function of time. The shift appears with the deuterium injection and is observed to some extent ever after termination of the injection. It $1 \mathrm{~s}$ explained by a toroldal rotation of the plasma due to momentum transier by the deuterium beams. The crystal spertrometer on Pox views the plasma under a angle of 16.5 degrees with respect to the radial direction, so that the component $v_{t}$ sin $\left(16.5^{\circ}\right)$ of the toroldal plasma velocity $v_{t}$ can be detected. on PDX the neutral beams are injected near-perpendlcularly, forming an angle of $14^{\circ}$ with the cadial direction at the center of the vacuum vessel. The deduced values of $1-2 \times 10^{7} \mathrm{~cm} / \mathrm{s}$ for the velocity of the toroidal plasma rotation represent a substantial fraction of the tangential component $\left[v_{d} \sin \left(14^{\circ}\right)=4.5 \times 10^{7} \mathrm{~cm} / \mathrm{s}\right]$ of the beam particle velocity. Measurements of the Doppler shift of the Ti XXI Ka-11ne can be used to deternine the momentum confinement time for the $T i$ XXI-impurity fons.

VII. CONCLUSION

The satellite spectra of helium-like fron and fitanlum, Fe XXV and Ti XXI, have been used as a diagmostic of the central ton and electron temperature in tokamak discharges. The experimental results are in good agreement with those obtained from different diagnostic methods, 1.e., analysis of charge-exchange neutrals and measurements of the electron cyclotron emission, and permit a detalled comparioon with theoretical 
predictions. Spectra of high $\mathrm{z}$ hellum-like long are observed for a wide range of experimental parameters and are of partlcular Interest as a diagnostic of the central ion temperature both in present-day and in future large size tokamaks. In addition to temperature measurements, the spectra can be used for determination of the charge-state alstribution, transport, and momentum confinement of impurity long in hot plasmas, and they also give valuable information on atomic data, e.g., the dielectronic recombination rate coefficient of hellum-like lons. Special emphasis has been given to a discussion of experimental conditions and instrumental requirements. 


\section{ACKONOWLEDMENTS}

The continued support of Drg. H.P. Furth, D.M. Meade, P.H. Rutherford, J.C. Hosea, and $\mathrm{K}$. Bol is gratefully acknowledged. We deeply appreclate the numerous discusfions with Drs. A.H. Gabriel, F Bely-Dubau, J. Dubau, P. Faucher, and $S$. volonté on the interpretation of the obgerved spectral data. We are grateful to Drs. A. Kritz and D. Batchelor for making their computer program for calculation of the Plasma Dispersion Function available to us, and we also gratefully acknowledge the technical assistance of J. Gorman, T.D. Cost, and the PLT technlcal crew under W. Mycock, and the assistance of the data processing group under L. Michaels. This work was supported by U.S. Department of Energy Contxact No. De-AC02-76-CHO-3073. 


\section{REFERENCES}

1H. Eubank et al., PLT Neutral Beam Heating Results, Princeton Plasma Physics Laboratory Report PPPL-1491 (November 1978) 47 pp; and Plasma Phys Ics and Controlled Nuclear Fusion Research (Proc. 7th Int. Conf. Innsbruck, 1978) 1 , IAEA VOI. I, $167(1979)$.

${ }^{2}$ J.C. Hosea et al., Plasma Physics and Controlled Nuclear Fusion Research, (Proc. 8th Int. Conf. Brussels, 1980) IAEA Vol. II, p. 95 (1980).

${ }^{3}$ K.M. Young, IEEE Trans. Nucl. Sci., NS-26, 1234 (1979).

4.W. Hill, M. Bitter, D. Eames, S. von Goeler, N.R. Sauthoff, and E. Silver, in Low Energy $x$-Ray Diagnostics - 1981, AIP Conference Proceedings No. 75, (American Institute of Phystcs, New York) pp. 8-24.

5.M. Young, "Nuclear Aspects of Tokamak Fusion Test Reactor (TFTR) Diagnostics and Instrumentation," Princeton Plasma Physics Laboratory Report, No. PPPL-1859 (1982).

6.S. Medley, S.L. Davis, and M. Brusat1, Princeton Plasma Physics Laboratory Report PPPL-1478 (1978).

${ }^{7}$ S. Suckewer and E. Hinnov, Nucl. Fusion 17945 (1977).

${ }^{8}$ S. Suckewer and E.HInnov, Phys. Rev. Lett. $\underline{41} 756$ (1978).

9F. Bely-Dubau, A.H. Gabriel, and S. Volonté, Mon. Not. Roy. Astron. Soc. 189 801 (1979), and $186405(1979)$.

${ }^{10}$ M. Bitter, s. von Goeler, K.W. Hill, R. Horton, D. Johnson, W. Roney, N. Sauthoff, E. S1lver, and w. Stodiek, Plys. Rev. Lett. 47921 (1981).

11J. Dubau and s. Volonté, Rep. Prog. Phys. 43199 (1980).

${ }^{12}$ U. Felaman, G.A. Doschek, R.H. Kreplin, and J.T. Moriska, Astrophys. J. 241 $1175(1980)$ 
13J.L. Culhane, A.H. Gabriel, L.w. Acton, C.R. Rapley, K.J. Phtllips, C. '. Wolfson, E. Antonucc1, R.D. Bentley, R.C. Catura, C. Jordan, M.A. Kayat, B.J. Kent, J.W. Lelbacher, A.N. Parmar, J.C. Sherman, L.A. Springer, K.T. strong, and N.J. Veck, Astrophys. J. 244 L141 (1981).

14.A. Gabriel, L.W. Acton, J.L. Culhane, K.J. H. Phillips, C.G. Rapley, E. Antonucci, R.D. Bentley, C. Jordan, M.A. Kayat, J.W. Lelbacher, M. Levay, J.C. Sherman, K.T. Strong, and N.J. Veck, Astrophys, J. 244 L147 (1981).

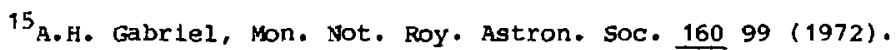

${ }^{16}$ C.P. Bhalla, A.H. Gabrlel, and L.P. Presnyakoy, Mon. Not. Roy. Astron. Soc. 172359 (1975).

${ }^{17}$ L.A. Vainshtein and U.I. Safronova, Atomic Data and Nuclear Dita Tables 21 $49-68(1978)$.

18 M. Bitter, K.W. Hill, N.R. Sauthoff, P.C. Efthimion, E. Mesryrvey, w. Roney, 5. von Goeler, R. Horton, M. Goldman, and w. Stodiek, Phys. Rev. Lett. 43129 (1979).

${ }^{19}$ L.A. Artsimovich, Nucl. Fuston 12215 (1972).

${ }^{20}$ H.P. Furth, Nucl. Fuston 15487 (1975); "U.S. Tokamak Research", Princeton plasma Physics Laboratory Report PPPL-1598 (1979).

21 s. von Goeler, "Diagnostic for Fuston Experiments" (Fergamon Press, Oxford and New York), edited by E. Sindoni and C. Wharton, 1979, p. 79.

${ }^{22}$ c. Jordan, Mon. Not. Roy. Astron. Soc. 142501 (1969).

${ }^{23}$ H.P. Summers, Mon. Not. Roy. Astron. Soc. 169663 (1974); Appleton Laboratory Report No. IM 367, (1975).

24A.L. Merts, R.D. Cowan, and N.H. Magee, Los Alamos Scientific Laboratory Report LA-6220-MS, 1976.

${ }^{25}$ C. Breton, C. DeMichaelis, M. Finkenthal, and M. Mattiol1, Association Euratom-C.E.A., Fontenay aux Roses, Report EUR-CEA-FC-948, (1978). 
${ }^{26}$ K.W. H1ll, S. von Goelex, M. B1tter, I. Canpbell, R.D. Cowan, B. Fraenkel, A. Greenbergex, R. Horton, J. Hovey, W. Roney, N. Sauthoff, and W. Stodiek, Phys. Rev. A19 1770 (1979).

27w. Stodiek et al., Plagma Physics and Controlled Nuclear Fusion Research Proc. 8th Int. Conf. Brussels, 1980, IAEA Vol. I, p. 9.

28 H. Johann, z. Phys. 69189 (1931).

29 K. Feser and A. Faessler, Z. Phys. 2091 (1968).

30 A. Unsöld, "Physik der Sternatmosphären" (Springer, Berlin-GöttingenHeidelberg, 1955).

${ }^{39}$ B.D. Fried and S.D. Conte, "The Plasma Disperston Function," (Academic Press, New York and London), 1961.

${ }^{32}$ P.C. Efthimion, v. Arunasalam, and J.C. Hosea, Phys. Rev. Lett. 44 $(1980)$

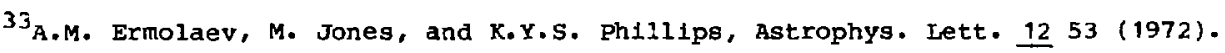
${ }^{34}$ L.A. Valnshtein and U.I. Safronova, Sov. Astron. AJ 15175 (1971). ${ }^{35}$ M. Bitter, S. von Goeler, N. Sauthoff, K.W. Hill, K. Brau, D. Eames, M. Goldman, i. Silver, and w. Stodlek, in "Inner-Shell and X-Ray Physics of Atoms and Solids" (Plenum Press, New York, and London) 1981, p. 861. 36 A.H. Gabriel, private communication. 
F1g. 1. Model of the PLT (Princeton Iarge Torus) tokamak. (PPPL-796171)

Fig. 2, Typical soft $x$-ray spectrum as observed from a PLT discharge with the Pulse Helght Analysis system. The spectrum shows the contributions of the bremsstrahlung and recombination continuum and high $\mathrm{z}$ impurity (Cr, Fe, Ni) line radiation. (PPPL-786492)

Fig. 3. Eractional abundance of the charge states of iron as a function of electron temperature for coronal equilibrium (c. Breton et al, Ref. 25). (PPPL-82X2025)

Fig. 4. Ka-line spectra of iron observed from PLT discharges with different electron temperatures. 26 The intensity is shifted to higher ionization states with increasing electron temperature. (PPPL-773660)

Fig. 5. Intensity [in photons $\left./\left(\mathrm{cm}^{3} \mathrm{sec}\right)\right]$ of the $\mathrm{Fe} X X V \mathrm{Ka}$-resonance line as a function of plasma radius. The calculations have been performed for different central electron temperatures, Te(0), assuming parabolic electron temperature and density profiles, and coronal equilibrium for the Fe XXV charge state. (PPPL-786242)

Fig. 6. Schematic of the Bragg curved crystal spectrometer. The photo shows the jig used for bending the crystal. (PPPL-773846)

Fig. 7. Schematic of the multiwire proportional counter and eiectronics. The detector was bullt by Grumman Aerospace corporation. (PPPL-773603) 
Fig. 8. Determination of the spectral resolution of the curved $(R=333 \mathrm{~cm})(22 \overline{4} \overline{3})$ quartz-crystal spectrometer, (a) Bragg reflection of the Holmium $I \alpha,-1$ ine $(E=6720 \mathrm{eV})$ as observed with a $.381 \mathrm{~mm}\left(.015^{\prime \prime}\right)$ wide slit positioned on the Rowland circle at the focal point for the $\mathrm{L} \alpha,-1$ ine. The experimental polnts represent an Image of the slit and can be fitted to a Gaussian with .497 mn FWHM. (b) Spatial resolution of the detector observed with an approximate zero width collimated $\mathrm{Fe}^{55}$ line source placed on the entrance window of the detector. The experimental points can be fitted to a Gaussian of $.369 \mathrm{~mm}$ FWHM, indicating that the resolution of the spectrometer is mainly determined by the spatial resrlution of the detector. (PPPL-786209; PPPL-786208)

Fig. 9. (a),(b) Dielectronic satellite spectrum of Fexxv as recorded by a multichannel analyzer from PLT for a central electron temperature of 1.65 and $2.30 \mathrm{keV}$, respectively. The photon energy decreases with increasing channel number. The conversion gain is 0.18 eV/channel. W Indicates the FeXXV Ka resonance line at $1.8500 \AA$. Also shown (solid curve) is the result of a least-squares fit of Voigt functions to the raw data of the most prominent peaks. (PPPL-793403)

Fig. 10. Experimental results for the intensity ratio of the dielectronic satellite $j$ and the resonance line $w$ and predictions of both the earlier ${ }^{15,16}$ (solid line) and most recent ${ }^{9}$ (dashed line) theories. The intensity ratios $I_{j} / I_{w}$ are plotted vs. the experimental values of $\mathrm{T}_{e}$ as determined from measurements of the electron cyclotron emission. ${ }^{32}$ (PPPL-793201) 
Fig. 11. Dielectronic satellite spectrum of $T i \mathrm{XXI}$. The spectrum has been observed from ohmically heated PDX diacharges with central electron temperatures of $\Rightarrow 1 \mathrm{kev}$, using the curved $(\mathrm{R}=363.5 \mathrm{~cm})(20 \overline{3} \overline{3})$ quartz-crystal spectrometer with a spectral resolution of $\lambda / \Delta \lambda=$ 23000. The wavelengths are given relative to the wavelength of the TiXXI Korresonance line using the theoretical value 36 of 2.6099 A. (PPPL-B06817)

Fig. 12. A time sequence of six out of sixteen $T i$ XXI ko-line profiles observed from pox discharges with additional ion heating by injection of intense ( $5 \mathrm{MM}, 47 \mathrm{kV})$ deuterium beams during the period from $300-450 \mathrm{msec}$. The solid Iines represent least-squares fit of voigt functions. The arrows indicate the limits used for the fit. (PPPL-89x0783)

Fig. 13. Ion temperature results obtained from the observed Ti XXI Ka-line profiles (circles) and from measurements of charge-exchange neutrals (triangle) as a function of time. The bars represent the statistical error of experimental results. (PPPL-8181209)

Fig. 14, Olserved Dopler-shift of the $\mathrm{Ti} X X \mathrm{~K} \alpha-1 i n e$ as a function of time. The Doppler-shift is due to a toroldal rotation of the plasma which results from momentum transfer by the injected deuterium beams. (PPPL-81X1337) 


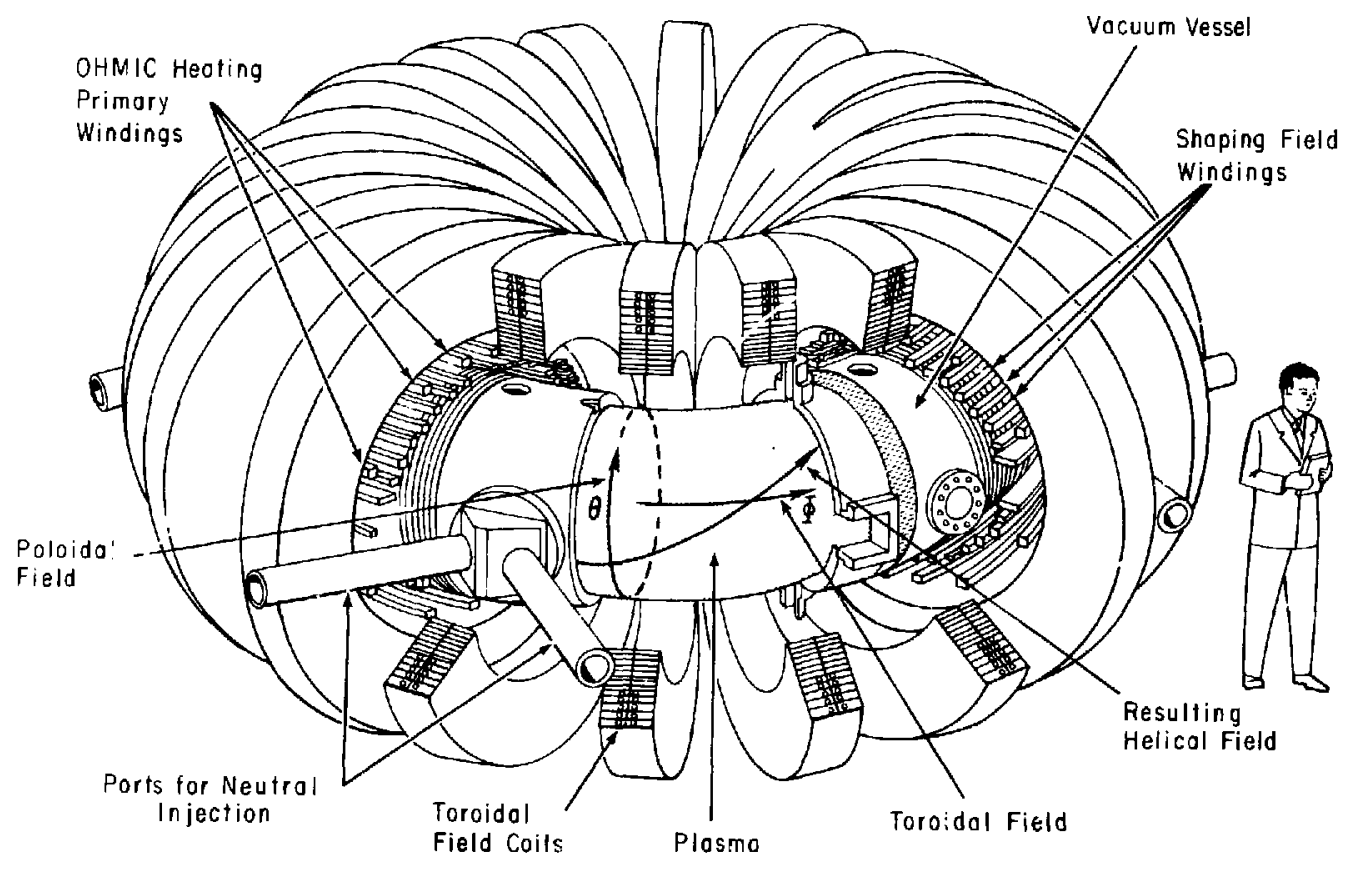




\section{LOG X-RAY INTENSITY (ARB. UNITS)}

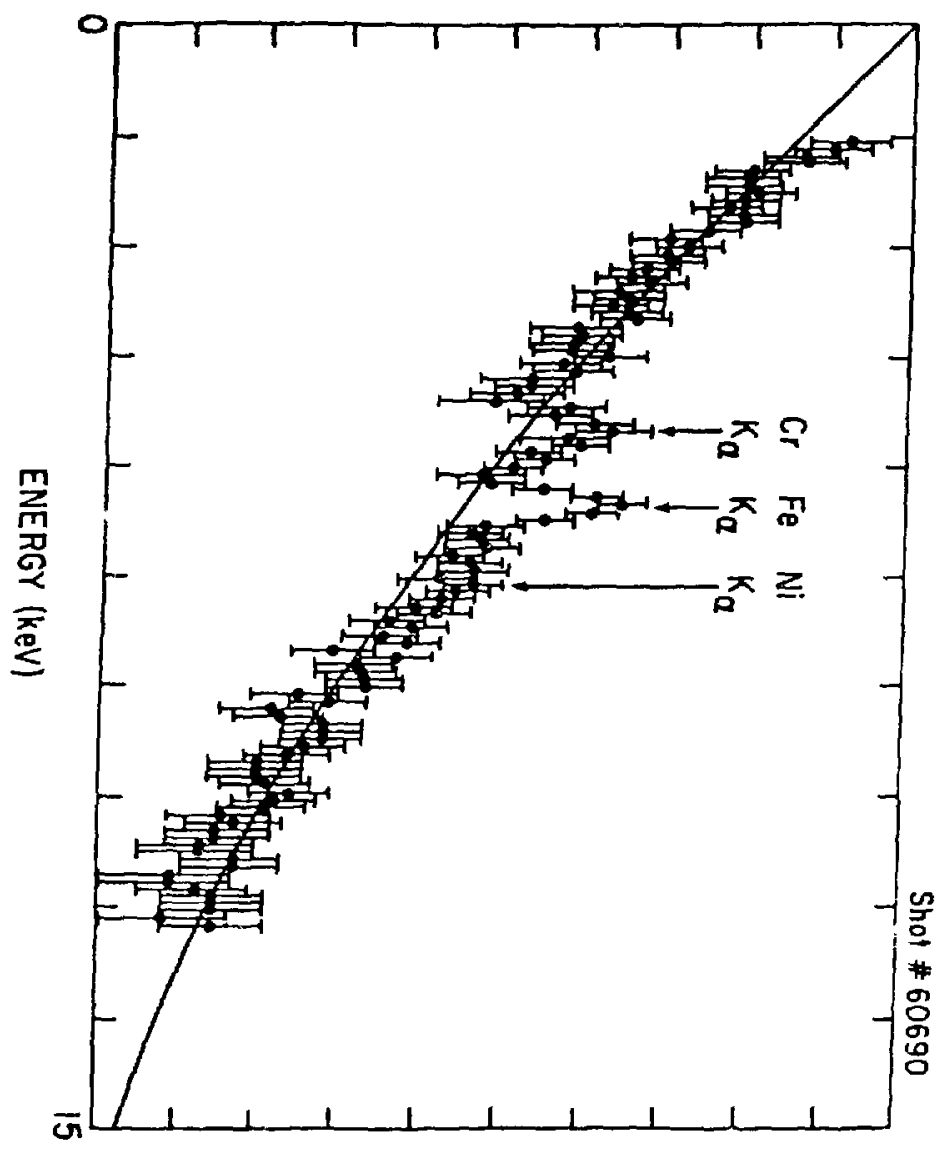




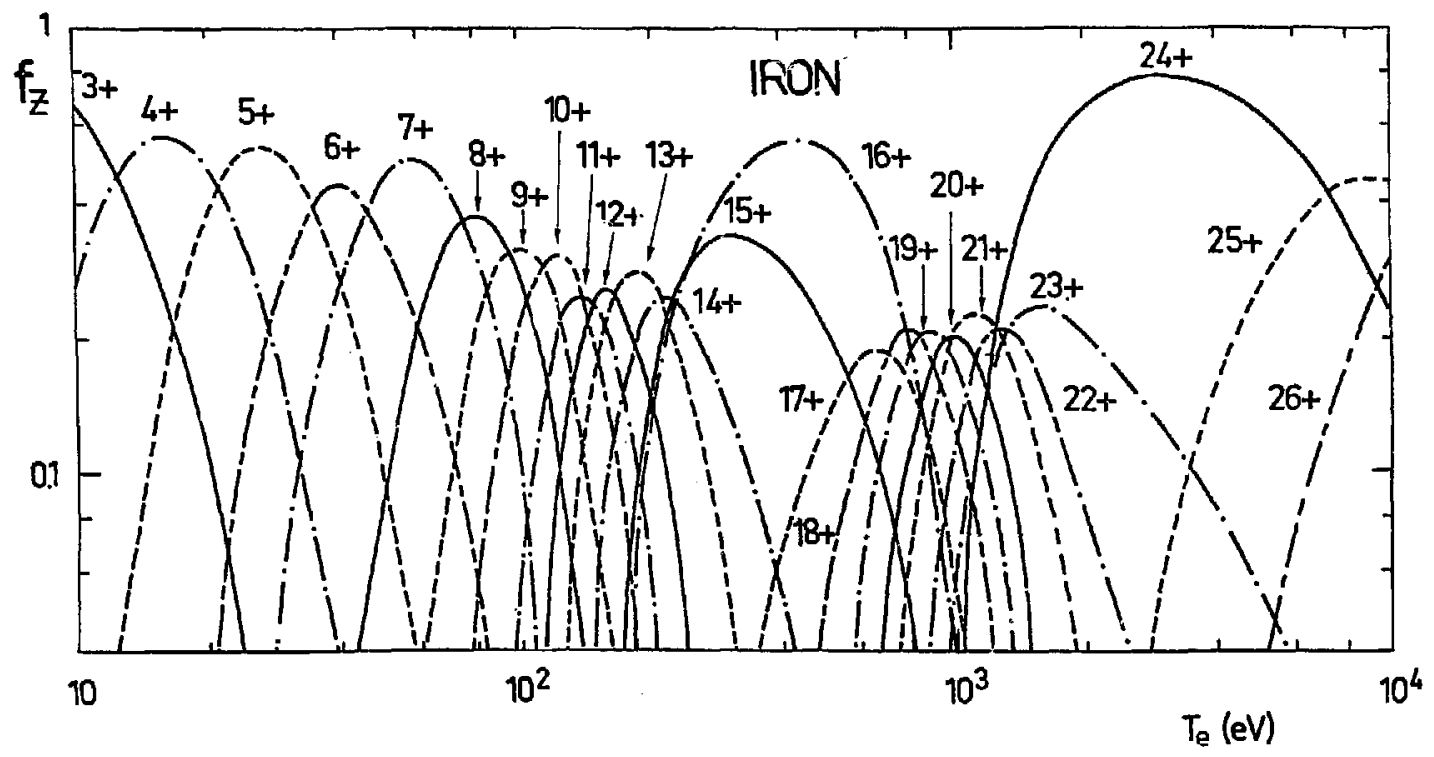




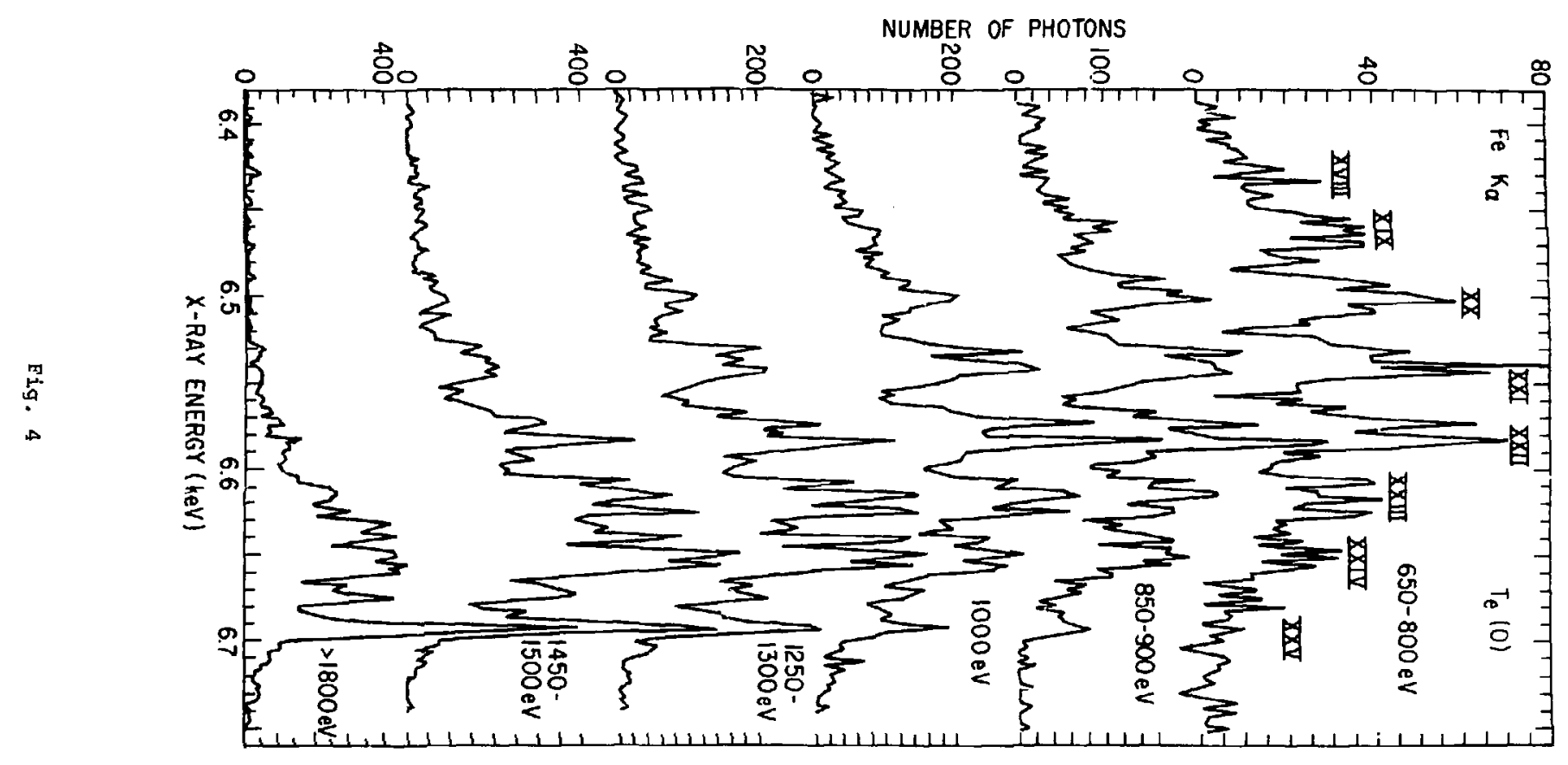




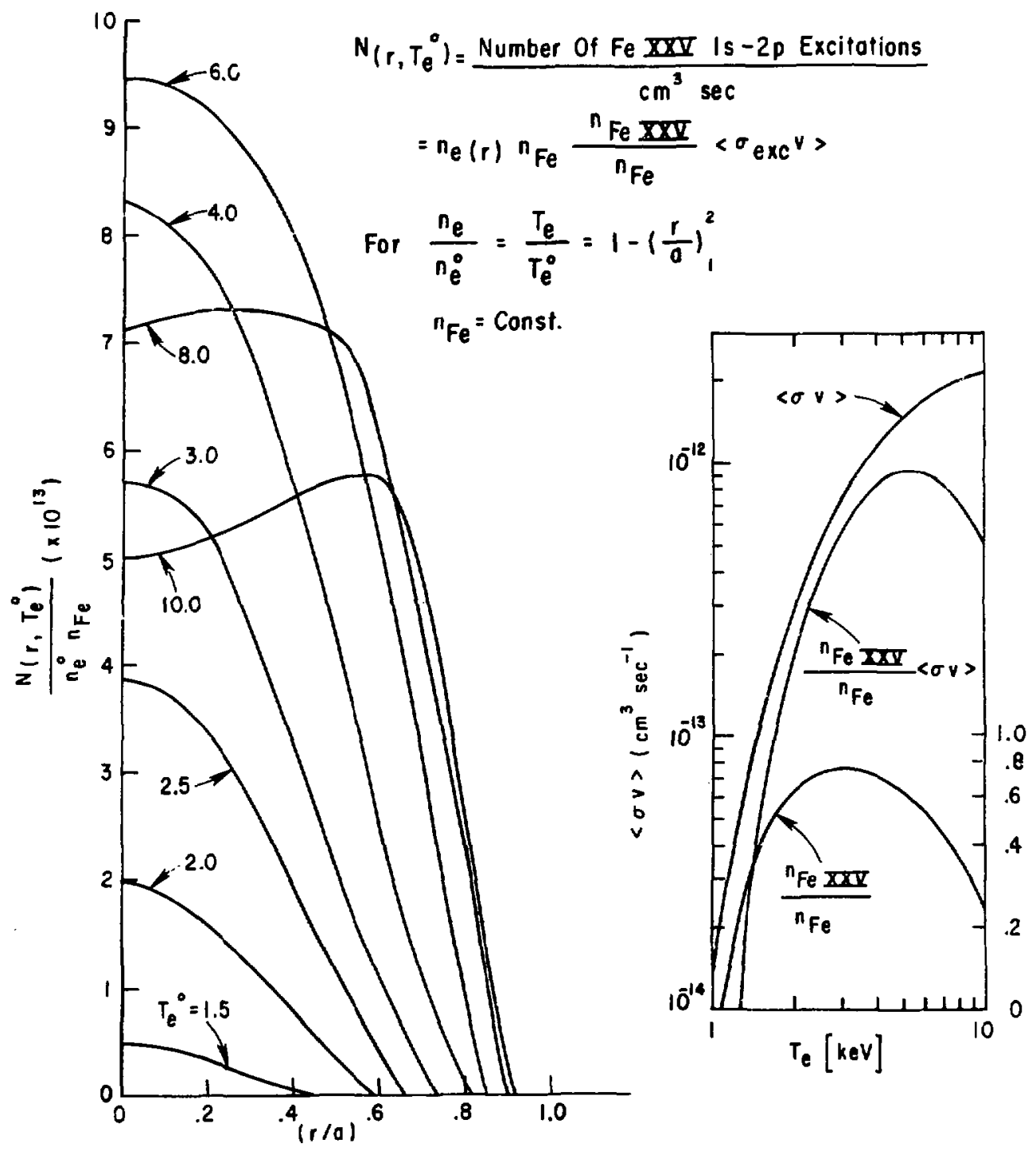




\section{CURVED - CRYSTAL SPECTROMETER}

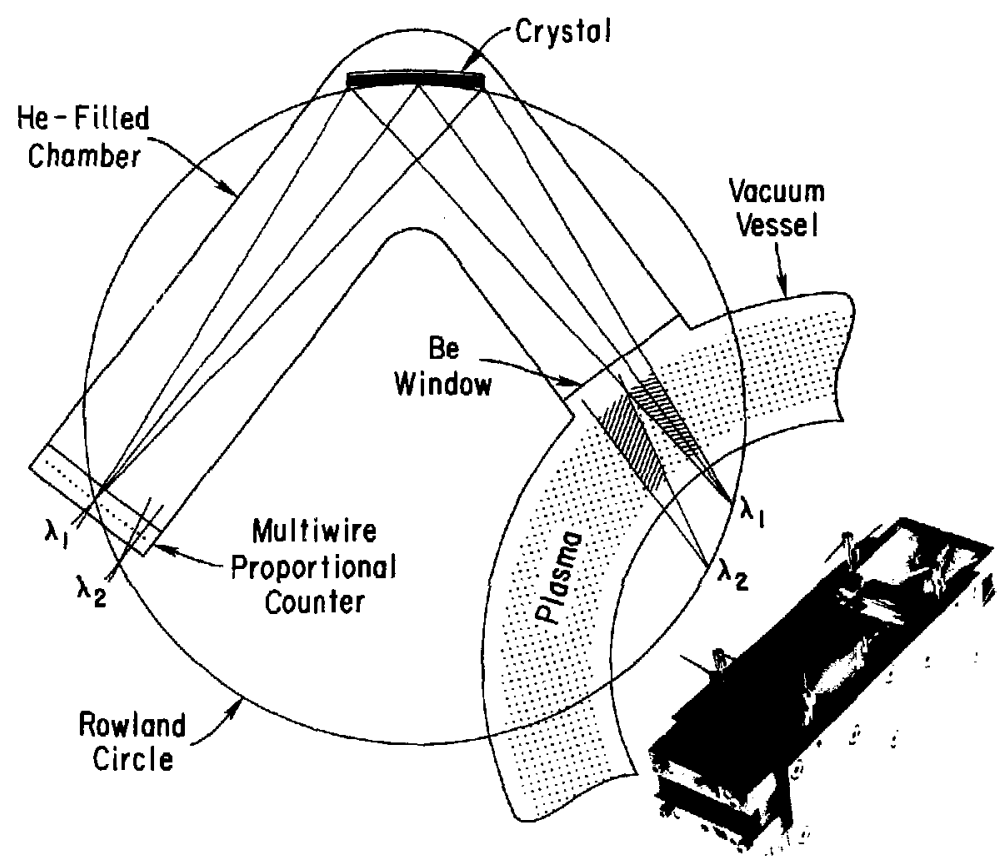


MULTIWIRE PROPORTIONAL COUNTER

AND ELECTRONICS

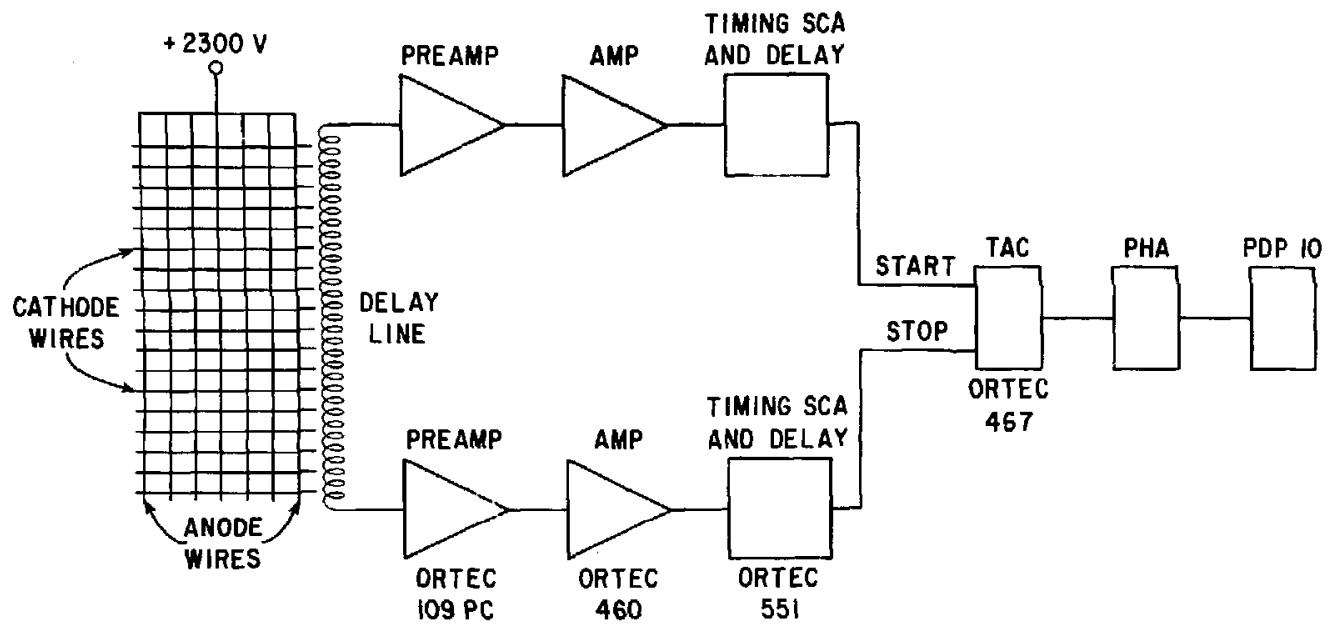




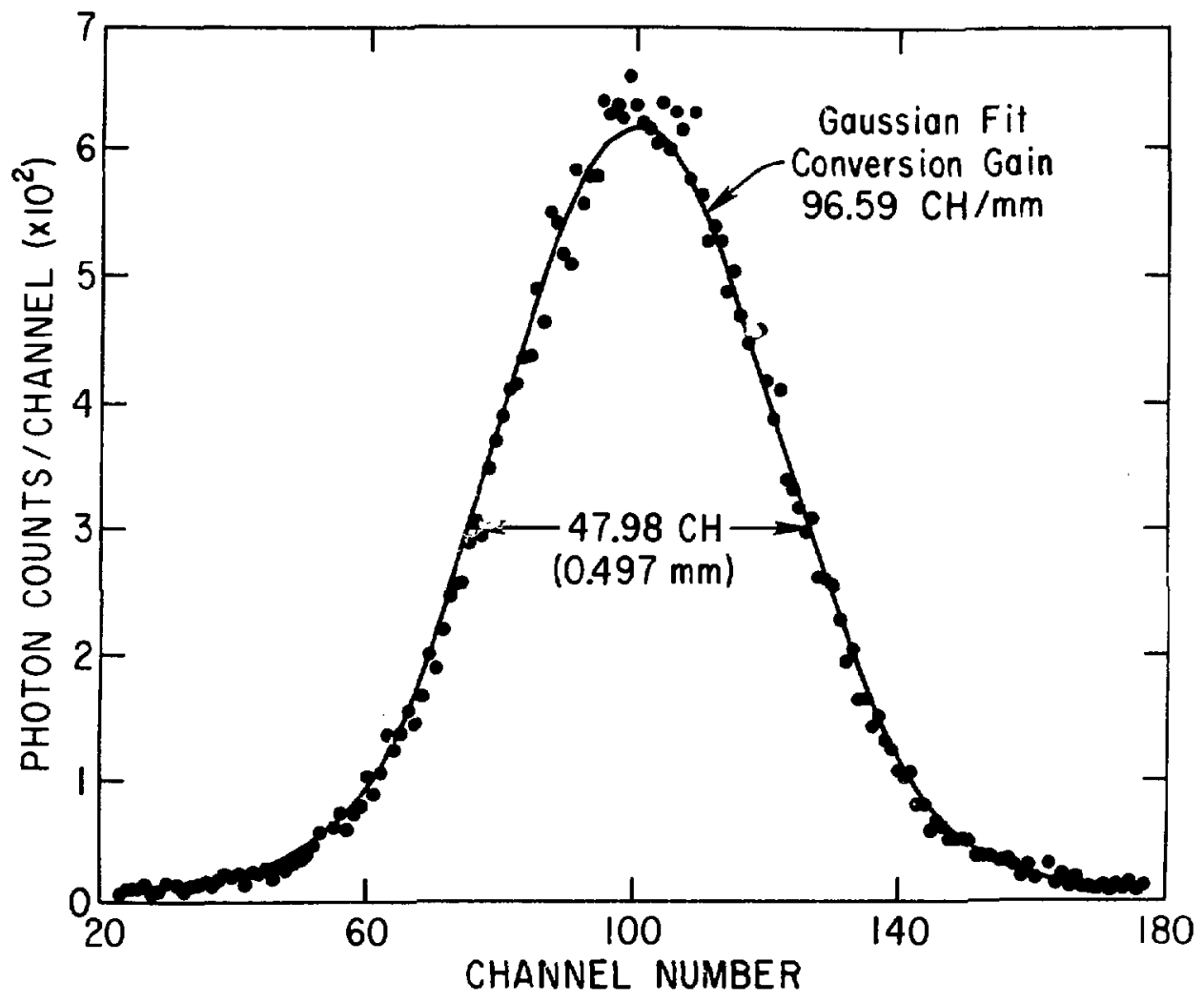

Fig. $8 a$ 


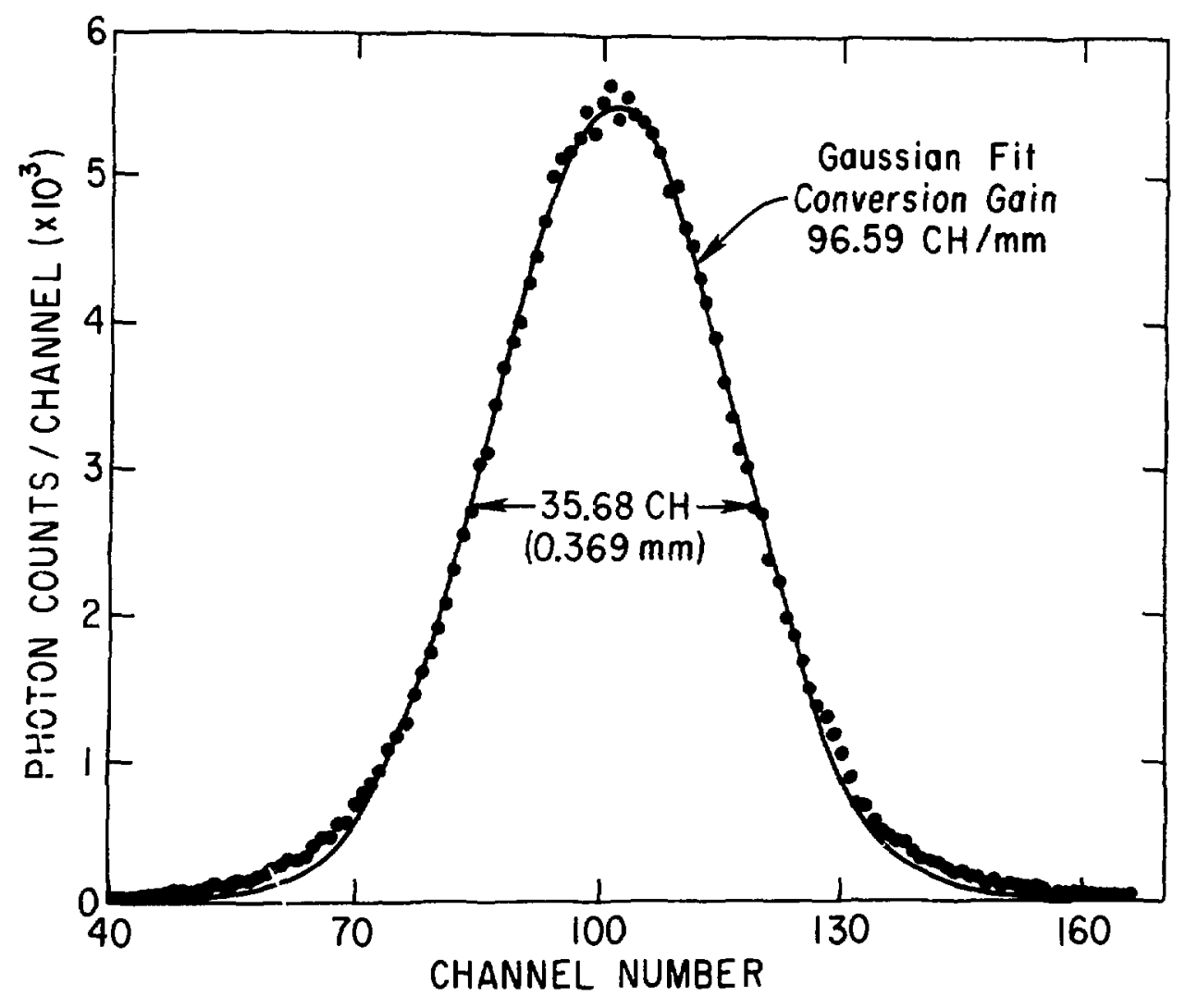

Fig. $8 b$ 


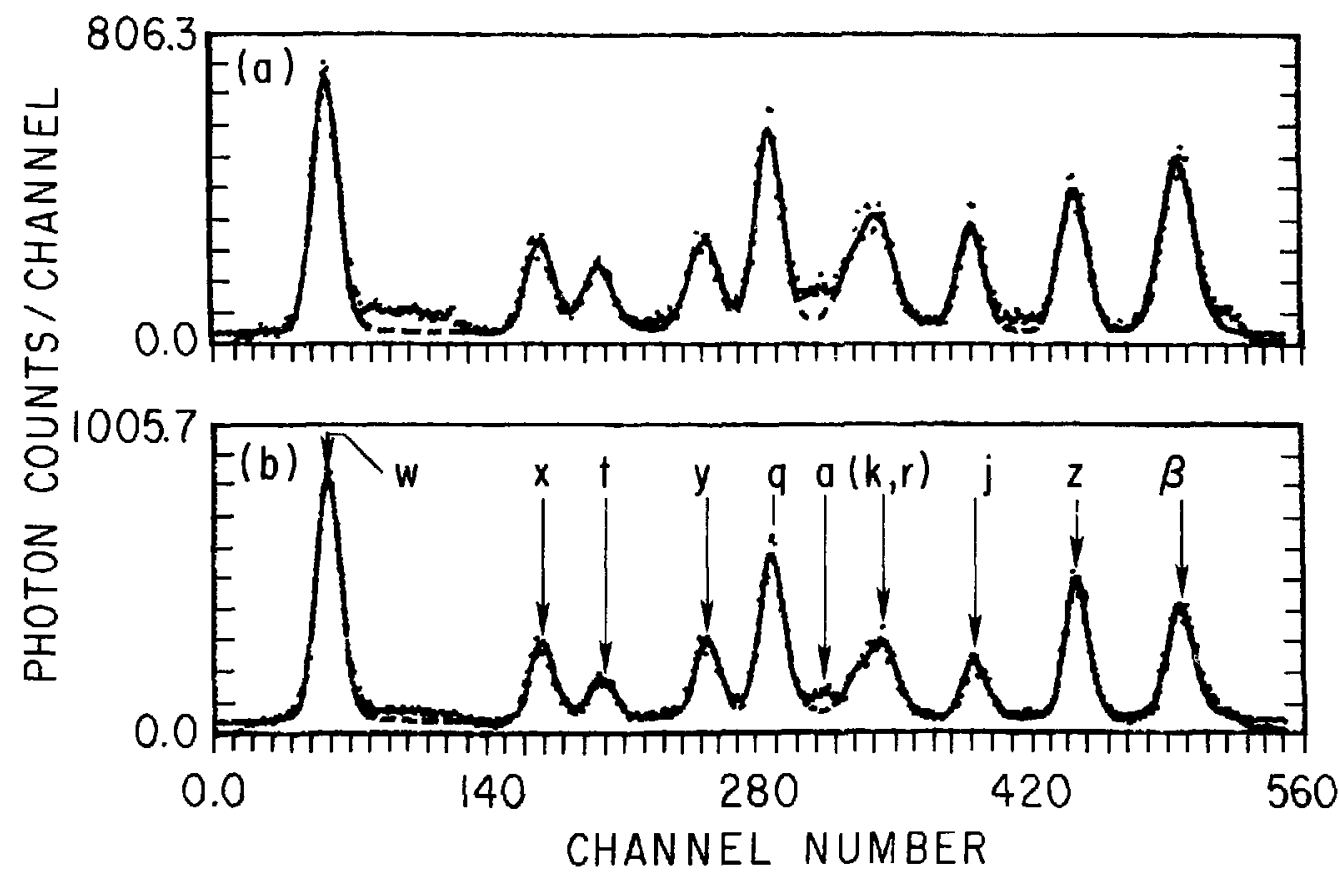




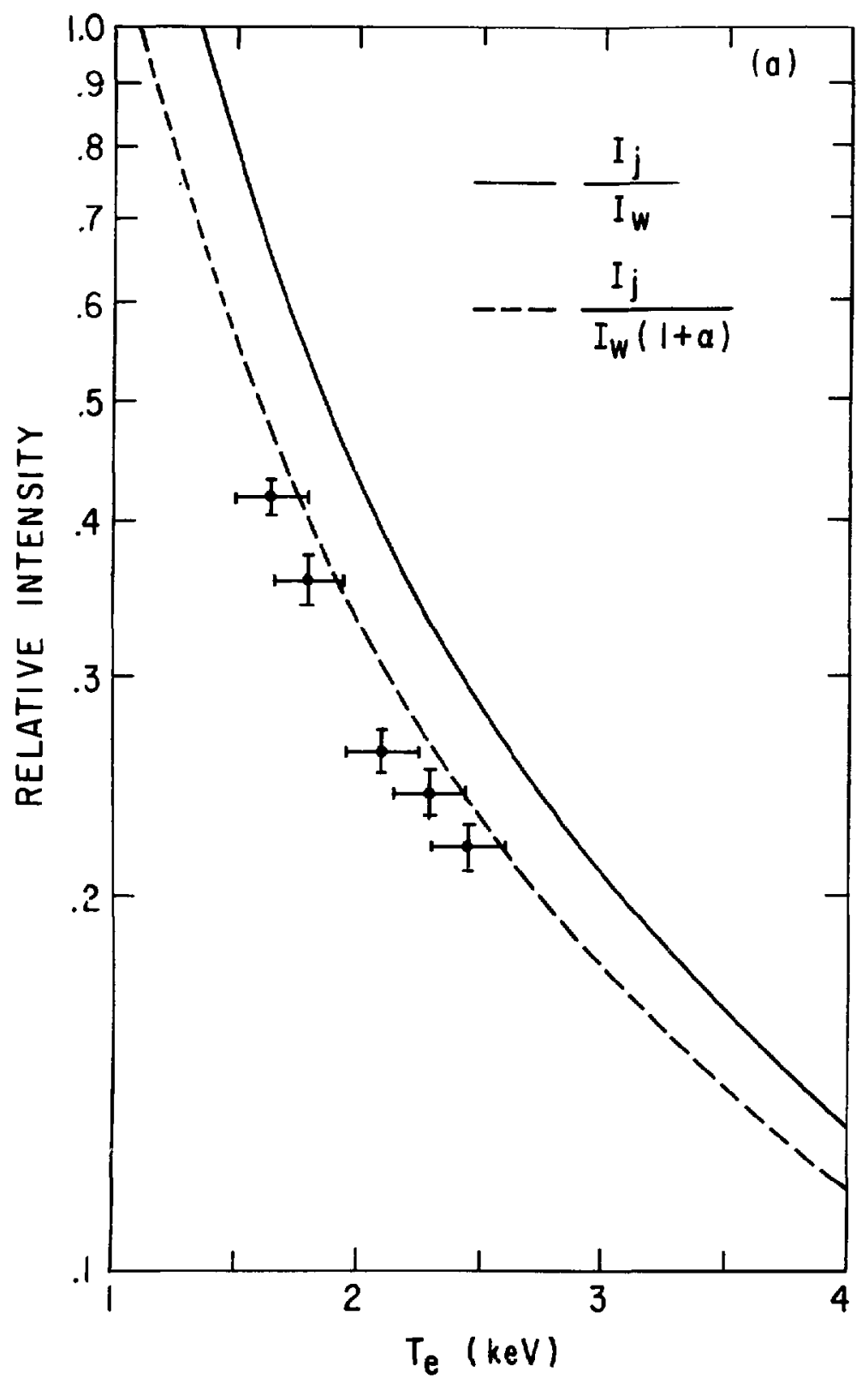

Fig. 10 


\section{DIELECTRONIC SATELLITE SPECTRUM \\ OF Ti XXI FROM PDX}
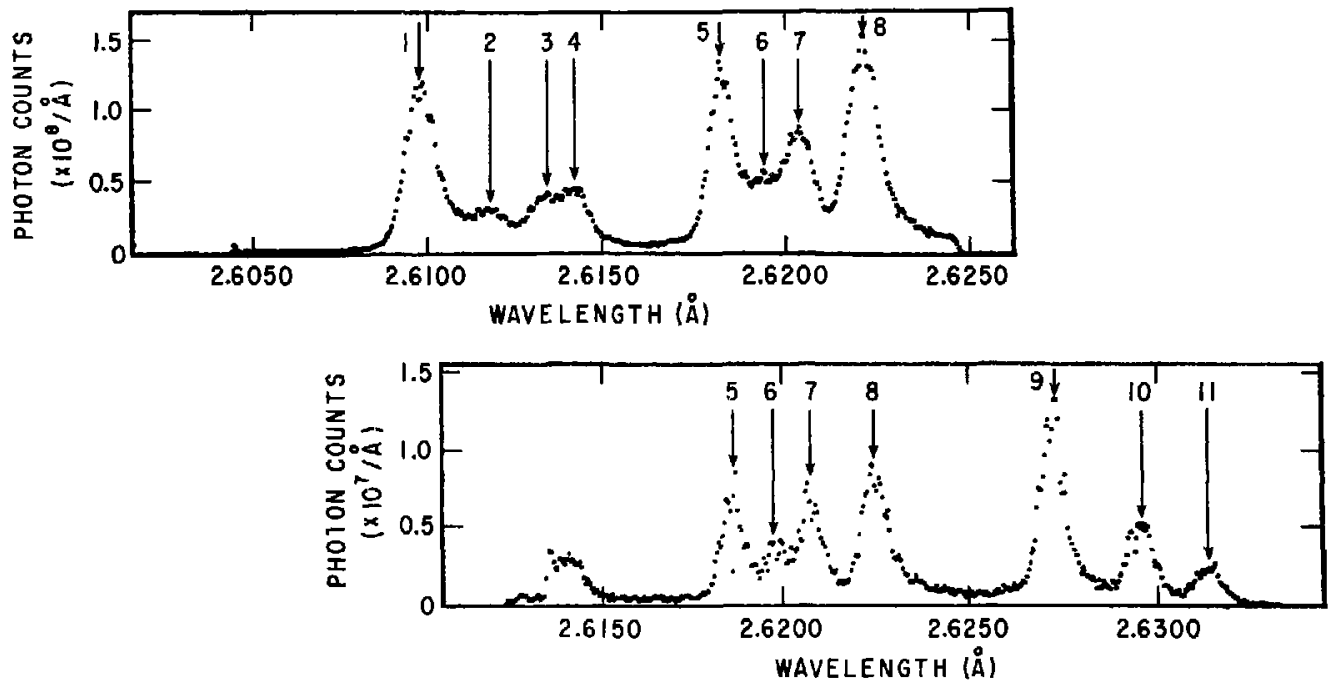

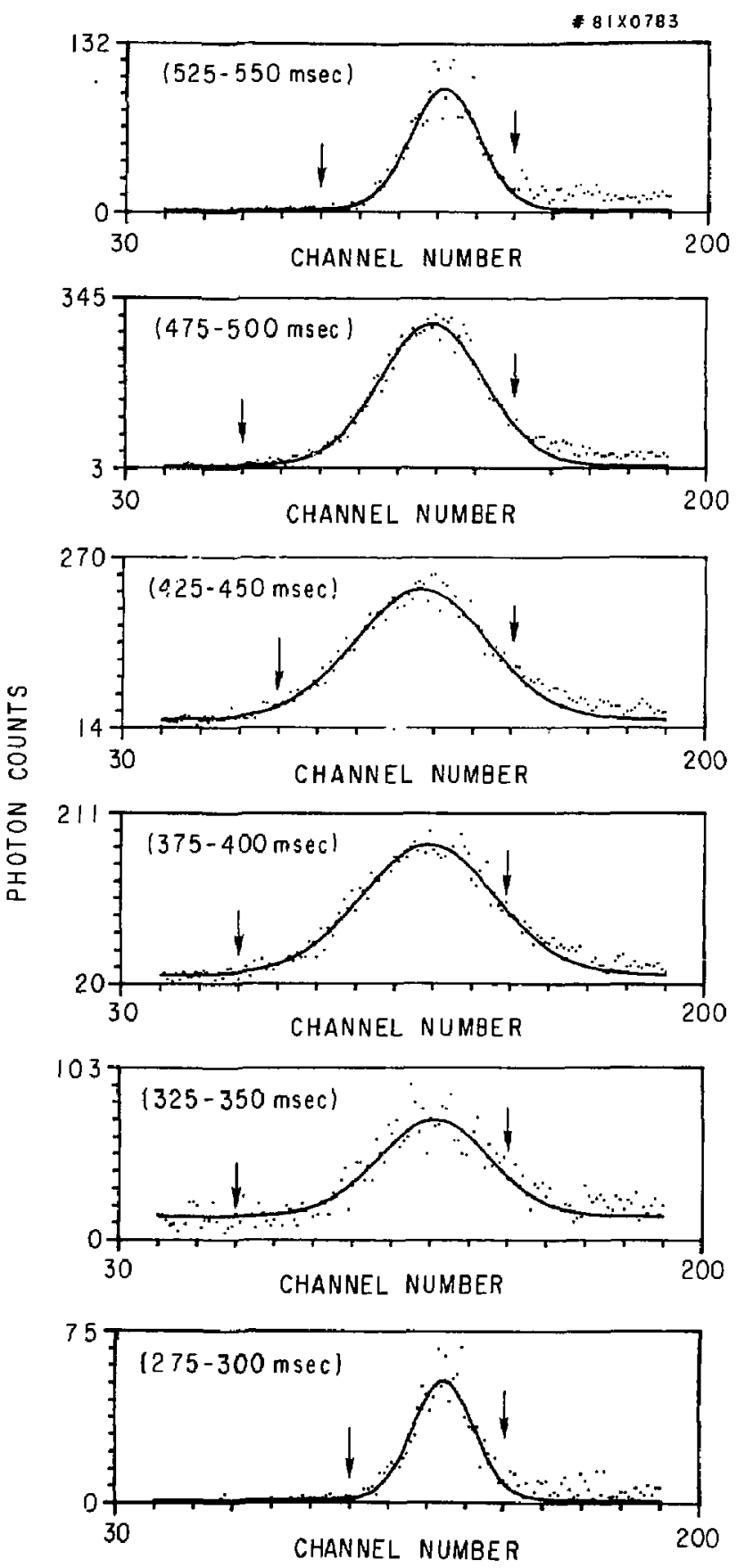

Fig. 12 
* $81 \times 1209$

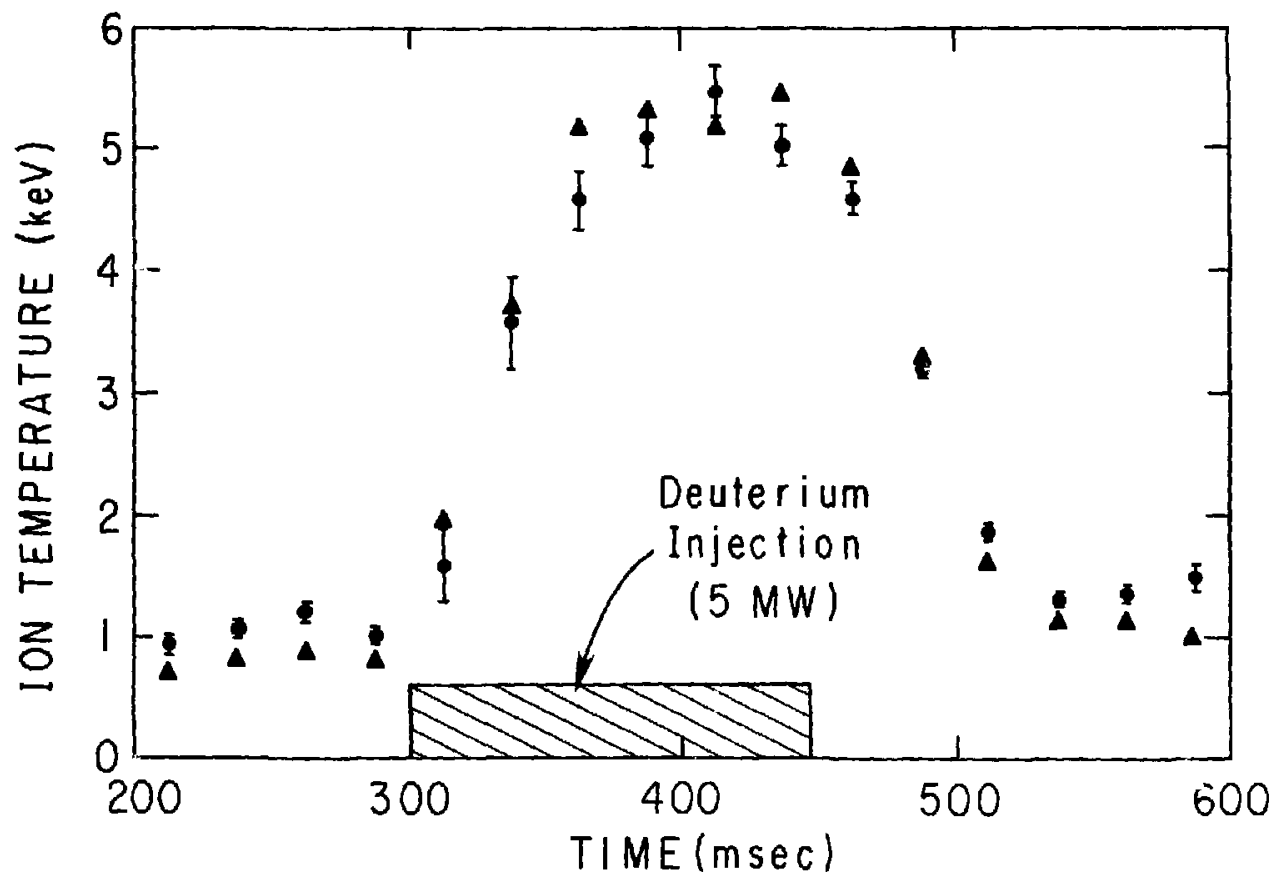




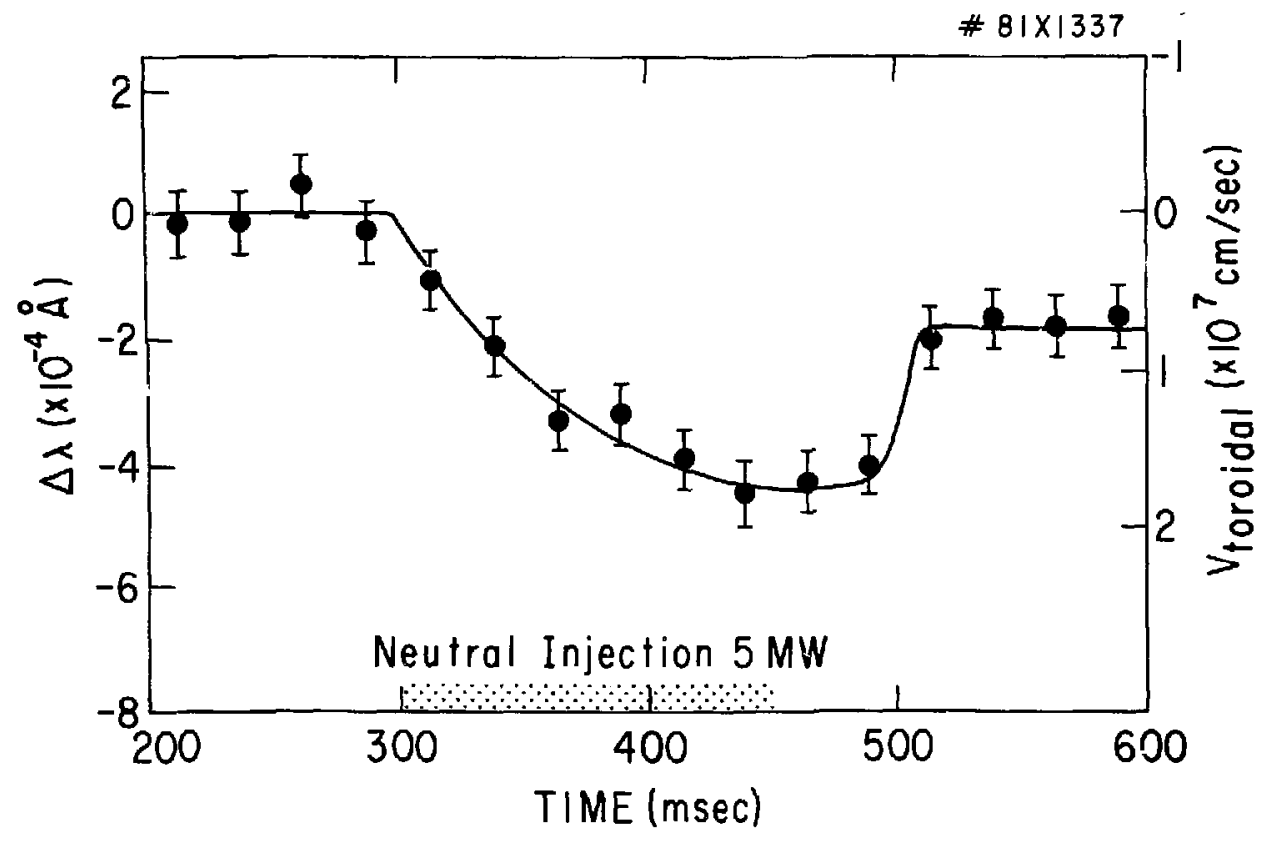

